\title{
External Imbalances, Gross Capital Flows and Sovereign Debt Crises
}

\author{
Sergio de Ferra*
}

January 2017

Download latest version

\begin{abstract}
The experience of the European monetary union has been characterized by three distinctive facts. First, core and periphery countries ran widening current account surplus and deficit positions, after the inception of the union. Second, core countries intermediated gross capital flows from the rest of the world, which in turn financed deficits in the periphery. Finally, a sovereign debt crisis took place, affecting multiple countries and causing severe recessions. I argue that institutional features of the European Economic and Monetary Union are responsible for the observation of imbalances, intermediation and pervasive crises. First, I show in a theoretical model that subsidies on holdings of euro-denominated assets contribute to all three phenomena. Second, I build a dynamic model of an economic union with trade in goods and financial assets. In the model, the introduction of a subsidy on cross-border asset holdings generates predictions for net and gross asset flows that quantitatively replicate the euro area experience. The model features a novel theoretical mechanism magnifying the severity of a debt crisis in an economic union, due to the joint presence of financial and trade linkages among union members. This mechanism is likely to have exacerbated the recent recession in the euro area periphery.
\end{abstract}

*Department of Economics. Stockholm University. E-mail: sergio.deferra@ne.su.se. I thank Gianluca Benigno and Wouter den Haan for invaluable support. I also thank Francesco Caselli, Alex Clymo, Luca Dedola, Roberto De Santis, Luca Fornaro, Réka Juhász, Kohei Kawaguchi, Andrea Lanteri, Jonathan Pinder, Markus Riegler, Federica Romei, Daniele Siena, Silvana Tenreyro, Shengxing Zhang and seminar participants at the EEA, LSE, University of Pavia, SAEe, Econometric Society European Winter Meetings, Bocconi, University of Vienna, University of Gothenburg, Uppsala University, Stockholm Univeristy, European Central Bank, HEC Montreal, Federal Reserve Board of Governors, University of Maryland, Ryerson University, Bank of England, University of Essex, BI Norwegian Business School and Bank of Italy for useful comments. 


\section{Introduction}

External imbalances, large gross capital flows and a pervasive sovereign debt crisis have characterized recent experience in the European monetary union. I introduce a framework to analyze jointly the determinants of these phenomena. This paper shows that by focusing on the introduction of policy distortions in the institutional framework of the European Economic and Monetary Union (EMU), we can shed light on important aspects of this experience. A specific feature of the monetary union, the presence of subsidies on cross-border asset holdings, plays a crucial role in generating widening current account deficit and surplus positions, an expansion of gross capital flows with the rest of the world and pervasiveness and severity of a sovereign debt crisis. In addition, in an economic union, trade integration among member countries contributes to the transmission and amplification of a debt crisis.

Three major facts can be isolated as the most salient in the recent experience of euro area economies. First, current account deficits and surpluses widened for members of the monetary union, from its inception in the early 2000s until the global financial crisis in 2008-09. Second, gross financial positions expanded in magnitude, with surplus economies in the euro area issuing gross liabilities to the rest of the world and intermediating resources to deficit countries 1 Third, a sovereign debt crisis took place in deficit countries. The crisis led to severe recessions in many countries, and to a collapse in net capital flows.

What role did institutional features of the EMU have in generating widening current account deficits, surpluses, and the expansion of gross asset and liability positions of euro area economies? How does trade integration among countries in an economic union affect severity and transmission of a debt crisis? This paper addresses these questions by developing a theoretical framework of capital flows and policy distortions in a union of countries. In addition, I introduce an infinite-horizon, heterogeneous-countries model to quantitatively assess the importance of the channels highlighted by the theoretical framework, in relation to recent experience in the EMU.

The theoretical framework highlights the main channel through which policy distortions affect capital flows in a union of countries. First, intermediation of gross capital flows emerges as union residents leverage a subsidy they enjoy on assets issued within the union by expanding their gross liability position against the rest of the world. Second, countries in the union run wider deficit and surplus positions due to the subsidy. Debtor countries benefit from lower borrowing costs, while savers are induced by policy distortions to further accumulate net assets. Importantly, the result of a widening current account surplus in saving countries is not mechanically due to the larger deficit of debtors, as the union is fully integrated in international financial markets. Finally, this framework highlights a novel mechanism leading to amplification of a debt crisis in

\footnotetext{
${ }^{1}$ This intermediation pattern has been documented by Waysand, Ross and de Guzman (2010) and Chen, Milesi-Ferretti and Tressel (2013). Hale and Obsfeldt (2014) document how borrowing from the rest of the world by banks in saving countries of the euro area helped fund their lending to deficit countries.
} 
an economic union. Financial linkages in the form of cross-border exposures transmit the crisis within the union. The interaction of financial linkages with trade integration, in turn, exacerbates the recession in debtor countries. Amplification arises as export destinations of crisis countries coincide with the creditors on whom they default, hampering the ability of debtors to export during a crisis. The economic intuition behind this channel is related to the "secondary" burden of a transfer suggested by Keynes (1929), following from a feedback effect between international transfers and changes in relative demand for goods.

I develop an infinite-horizon model of an economic union, represented by a continuum of countries trading in heterogeneous goods and assets, both internally and with the rest of the world. The model allows for a quantitative analysis of the effects of policy distortions in the euro area, and it is calibrated to replicate key features of countries in the monetary union. First, the model replicates the widening of the net foreign asset distribution observed after the inception of the EMU. Second, predictions of the model for net and gross capital flows replicate the experience of external imbalances and gross capital flow intermediation observed in the euro area. In the model, the introduction of a subsidy on cross-border asset holdings has non-linear effects on endogenous choices of the heterogeneous countries that constitute the union, depending on their position in the net foreign asset distribution. Finally, the model can be employed to analyze general equilibrium transmission and amplification of a debt crisis in an economic union, taking place via the external balance sheet of savers and through trade among union members.

The phenomena at the center of this analysis have been very significant in terms of their size, including the occurrence of a rare sovereign debt crisis in advanced economies. First, current account surplus and deficit positions in the core and periphery of the euro area both approached at their peak $3 \%$ of GDP of the monetary union 2 Second, the expansion in gross flows brought the sum of gross asset and liabilities of the euro area against the rest of the world to $350 \%$ of GDP in 2007, a figure $50 \%$ higher than the one observed in the United States. Third, the output contraction associated with the debt crisis in peripheral countries amounted to 5\% of GDP, between 2011 and 2013. The recovery in core countries slowed down significantly as well, with GDP growing by $1 \%$ only in the three years to 2013. In comparison, in the United States, GDP grew by $7 \%$ in the same period. Finally, I provide concrete examples of distortions subsidizing residents' purchases of assets issued by union-member economies in the EMU. These implicit subsidies take the form of financial regulation provisions on holdings of sovereign debt, the ability to use certain types of assets as collateral in transactions with the European Central Bank, as well as implicit expectations of bailouts on the part of asset holders.

An important contribution of this paper lies in the analysis of trade in financial assets between a union of countries and the rest of the world. Capital flows between the euro area and the rest of the world have largely been overlooked by the literature on the Eurozone

\footnotetext{
${ }^{2}$ Throughout this paper, the definition of core and periphery countries adopted will be the conventional one, with surplus countries Austria, Belgium, France, Germany and the Netherlands in the former group and deficit countries Greece, Ireland, Italy, Portugal and Spain in the latter.
} 
debt crisis. Current account surplus and deficit positions of core and peripheral countries were similar in magnitude in the period leading up to the crisis. Papers in this strand of the literature, then, have typically analyzed the crisis episode by modeling the monetary union as a set of open economies trading solely among each other 3 The euro area, however, is closely integrated with international financial markets, displaying large gross asset and liability positions against the rest of the world. The analysis of trade in financial assets with the rest of the world allows for an investigation of two important issues. First, what factors induced core countries to save in the periphery, intermediating in addition resources borrowed from the rest of the world? Second, what are the implications of large gross external positions, as distinct from those of net ones? This latter issue appears to be especially important in the context of the euro area, where the external balance sheet of core countries featured asset and liability sides that were mismatched along important dimensions, notably in terms of nationality of counterparties.

The next subsection reviews the contribution of this paper to the existing literature. Section 2 presents evidence on net and gross capital flows in the euro area, on the presence of distortions affecting trade in euro-denominated debt and on heterogeneous exposure to intra-union trade for European countries. In Section 3, I introduce the theoretical framework and I analyze the implications of a subsidy on asset holdings on current account imbalances, intermediation of gross capital flows and crisis. Section 4 presents the infinitehorizon model with heterogeneous countries, and quantitative results on the effects of policy distortions and of a debt crisis in an economic union. Section 5 concludes.

Literature review. A growing body of research has recently analyzed the European experience of current account imbalances, gross capital flows and sovereign debt crisis. This paper contributes to that literature, focusing on the role of policy distortions in generating intermediation of gross capital flows by the core to the periphery and widening current account deficits and surpluses. In addition, I analyze how the interaction between financial linkages and trade integration in an economic union generates contagion and amplification of a debt crisis.

The emphasis in this paper on the effects of policy distortions on capital flows in the euro area is motivated by the evidence on gross external positions presented by Waysand, Ross and de Guzman (2010) and Chen, Milesi-Ferretti and Tressel (2013). The latter suggest that core countries' intermediation behavior may have been induced by the presence of regulatory distortions in the EMU, leading them to issue gross liabilities to extra-euro area economies to finance lending to the periphery. Following that suggestion, I investigate in the context of a model the ability of subsidies on cross-border holdings of assets in an economic union to explain the observation of intermediation of gross capital flows and current account imbalances.

Hale and Obstfeld (2014) also provide evidence on the impact of the introduction of the EMU on international debt flows. In addition, they present a model where a reduction in financial transaction costs induces intermediation of capital flows by banks in the core.

\footnotetext{
${ }^{3}$ Notable examples are Martin and Philippon (2015), Corsetti, Kuester, Meier, Müller (2014) and Guerrieri, Iacoviello and Minetti (2013).
} 
I describe here the implications of a similar distortion on intra-EMU trade in financial assets on net and gross financial positions. I analyze, in addition, crisis transmission and amplification effects of such a distortion, as well as providing an assessment of the optimality of its introduction.

The modelling approach adopted in my infinite horizon model is to describe the world economy as a continuum of countries subject to idiosyncratic income shocks, analyzing current account and external financial positions in this setting. I extend the traditional framework introduced by Clarida (1990) to allow a continuum of small open economies to trade risky assets with a large rest of the world. This extension, motivated by the observation that European economies engage in extensive financial trade with global financial markets, allows me to analyze motives inducing countries in the euro area core to hold positive financial positions against partners in the EMU, while being gross debtors with respect to extra-union economies. Fornaro (2014) employs a similar framework to analyze the effects of a deleveraging episode taking place in a monetary union. Here, the introduction of trade in goods and assets with the rest of the world allows me to analyze gross capital flows and the heterogeneous effects of a debt crisis on countries with varying exposure to trade with their union partners.

By analyzing transmission and amplification of a debt crisis in an economic union, this paper is related to a rich literature on the Eurozone debt crisis 4 Two key features define the economic union presented in this paper. First, the presence of regulatory distortions affecting trade in assets issued within the union induces in equilibrium the creation of financial linkages among union members. A similar feature characterizes the economic union introduced by Broner, Erce, Martin and Ventura (2014). There, residents of a union share the preferential treatment given to domestic creditors by a sovereign debtor in default. Arellano and Bai (2014) also analyze contagion of a debt crisis when several countries borrow from a common lender. Secondly, countries in an economic union are tied in my model by close trade integration. In the model, asymmetric trade integration follows from lower transport costs that apply to trade in goods within the union. Anderson and van Wincoop (2004) document the presence of large variability in trade costs across goods and country pairs. Following Sachs (1982), I introduce heterogeneous goods, characterized by differences in transport costs. In my model, countries in the union differ in terms of specialization in output goods characterized by different degrees of tradability. Heterogeneous specialization determines different exposure of member economies to trade with union partners. In turn, asymmetric exposure to trade with union partners determines asymmetric amplification effects of a crisis episode. A similar feature is present in Benigno and Romei (2014), where fluctuations in the real exchange rate arising during a debt deleveraging episode have heterogeneous effects on countries specialized in production of different goods.

In my model, distortions on cross-border holdings of assets affect households' portfolio allocation problem. In particular, households that are offered a bailout promise

\footnotetext{
${ }^{4}$ A non-exhaustive list includes Aguiar, Amador, Farhi and Gopinath (2015), Guerrieri, Iacoviello and Minetti (2013), Martin and Philippon (2015), Corsetti, Kuester, Meier and Müller (2014) and Lane (2012).
} 
fail to internalize the risk of losses associated with their purchases of gross assets. In Mendoza (2010), Bianchi (2011) and Benigno, Chen, Otrok, Rebucci and Young (2013) a similar externality is present. In those papers, however, a pecuniary externality arises as households do not take into account effects of their borrowing decision on a key relative price, determining in turn the severity of a borrowing constraint. Here the externality mainly affects countries with a positive net foreign asset position, where households' saving decision is critically affected by the presence of a bailout promise.

\section{Empirical evidence}

I present in this section the main empirical evidence that motivates this paper. First, I detail facts related to the widening of current account deficit and surplus positions observed in the euro area in the 2000s. Second, I describe evidence on the expansion of gross external asset and liability positions of euro area economies and on the pattern of intermediation of international capital flows. Third, I will present specific features of the regulatory and policy framework that have contributed to subsidize cross-border holdings of assets within the euro area. Finally, I present a measure of euro area economies' exposure to trade with European partners. This indicator will be crucial to determine the direction of the effect, in a crisis, of the interaction between financial linkages and trade integration.

Current account imbalances in the euro area. Current account dynamics of economies in the euro area displayed significant imbalances in the years preceding the global financial crisis, an observation that has been widely documented in the literature 5 Figure 1 displays the sum of current account balances for countries in the two groups of core and periphery members of the monetary union, expressed as ratios to euro area GDP6 The gap in current account balances between countries in these two groups widened substantially in the period from the inception of the EMU to the global financial crisis. The current account surplus in core countries approached $3 \%$ of euro area GDP in 2007, from a balanced position in 2000. In the periphery, the current account deficit doubled in the same period, rising above $2 \%$ of euro area GDP in 2007.

Disaggregated data for individual countries are reported in Figure 2, In the periphery, the current account deficit rose in all countries but Portugal between 2000 and 2008. Prior to the global financial crisis, the current account deficit was above $10 \%$ of GDP in Portugal and Greece and above 5\% in Ireland and Spain. Among core countries, the largest rise in current account surplus was observed in Austria, Germany and the Netherlands. At its peak, in 2007, the German current account surplus amounted to $7 \%$ of GDP. A different

\footnotetext{
${ }^{5}$ For a detailed review of the pattern of capital flows in the EMU, see Lane (2013). The pattern of current account imbalances in the euro area has been recently analyzed in the context of a theoretical model by Siena (2015) and Jaccard and Smets (2015), among others.

${ }^{6}$ As already mentioned, the core includes Austria, Belgium, France, Germany and Netherlands. The periphery includes Greece, Ireland, Italy, Portugal and Spain.
} 


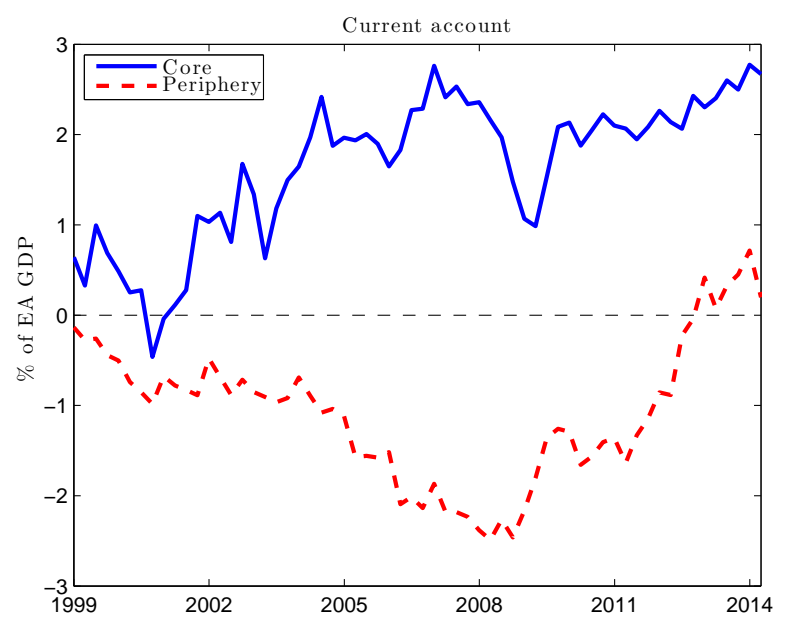

Figure 1: Current account balances of core and periphery countries in the euro area, as fraction of total euro area GDP. Core includes Austria, Belgium, France, Germany and Netherlands. Periphery includes Greece, Ireland, Italy, Portugal and Spain.

pattern was observed in France and Belgium, where the surplus diminished in magnitude throughout this period.

Financial linkages and intermediation. Two key facts emerge from the analysis of bilateral international investment positions of euro area economies 7 First, strong financial linkages tied together economies in the EMU, with large, and growing, cross-border positions among euro area economies. Second, euro area economies traded extensively in financial assets with the rest of the world, with an emerging pattern of intermediation by core countries of capital flows from outside the euro area.

Data on net and gross financial positions of euro area economies reveal the presence of close interdependence among these countries. First, the fraction of total gross external positions of economies in the EMU accounted for by euro area counterparties was equal to approximately half of their total gross positions. Second, economies in the euro area core represented major financial partners for peripheral countries. Gross liabilities of peripheral countries held by Germany, France and the Netherlands in 2008 ranged from $40 \%$ of GDP for Italy to $69 \%$ of GDP in Portugal 8 Gross liabilities held by the three major core countries were even higher for Ireland, amounting to $268 \%$ of Irish GDP 9 Finally, global international investment positions of peripheral countries could largely be

\footnotetext{
${ }^{7}$ All figures reported in this subsection are drawn from the dataset and paper presented by Waysand, Ross, de Guzman (2010).

${ }^{8}$ In addition, substantial amounts of liabilities corresponding to counterparties in the United Kingdom and Luxembourg are likely to partly reflect claimants ultimately based in the euro area core. Waysand, Ross, de Guzman (2010) discuss the merits of alternative residence reporting principles.

${ }^{9}$ The pattern observed in Ireland, however, is substantially different from the one of Italy, Spain, Portugal and Greece. Ireland, in fact, held a substantial amount of gross assets outside the euro area, amounting to approximately $400 \%$ of GDP just for the United Kingdom and the United States.
} 

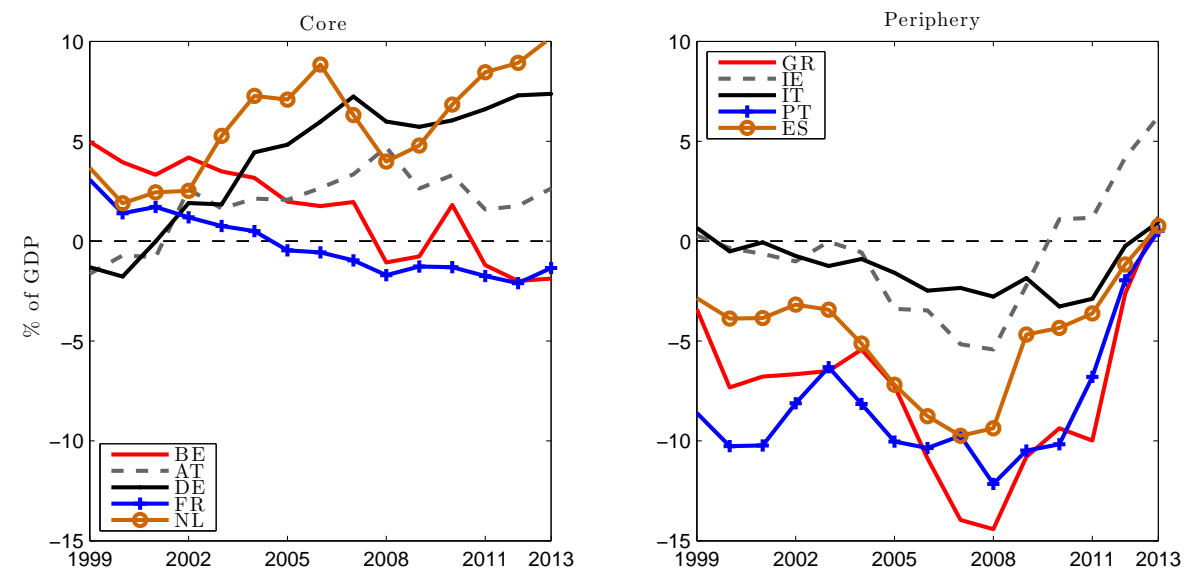

Figure 2: Current account balances of selected countries in the euro area, as fraction of individual GDP. The left-hand side panel represents so-called core countries, while the periphery is displayed in the right-hand side panel.

explained by the bilateral positions of these countries against euro area partners. The fraction of the global international investment position of peripheral countries represented by their bilateral position against euro area partners ranged between $61 \%$ for Portugal to $80 \%$ for Greece, in 2008, highlighting how the majority of these countries' trade in financial assets took place within the EMU 10

Trade in financial assets by economies in the euro area with the rest of the world was characterized by two main features. First, the evolution of gross financial positions of core euro area economies can be interpreted as describing intermediation of international capital flows by these countries. The bilateral international investment position of core economies with respect to the rest of the euro area rose between 2002 and 2007. This increase ranged between 30 percentage points of GDP for Belgium to 12 percentage points in France. At the same time, the global international investment position was deteriorating for some of these countries, signalling that they were funding gross saving in the euro area by borrowing from the rest of the world, rather than by increasing their net savings 11 In Germany, the global international investment position was also growing at the time, but by less than the bilateral one with the euro area, so that the bilateral investment position with respect to the rest of the world was deteriorating.

Second, the magnitude of gross external positions of the euro area with the rest of the world was large by international standards, highlighting its financial openness and close integration with world financial markets. While the external net foreign asset position of

\footnotetext{
${ }^{10}$ Again, the pattern is different in the case of Ireland. Given substantial holdings of gross assets outside the euro area, its global international investment position amounted to $-56 \%$ of GDP, while its bilateral position against the rest of the euro area amounted to $-123 \%$ of GDP.

${ }^{11}$ In France, Belgium and Austria, the global international investment position deteriorated by 14, 10 and 7 percentage points of GDP, respectively, between 2002 and 2008. In the Netherlands, on the other hand, a substantial improvement in the global international investment position was matched by a smaller one in the bilateral one with euro area partners.
} 
the euro area was small when compared to that of the United States or Japan, the sum of its gross external asset and liabilities amounted to 350\% of GDP in 2008, compared with less than 250\% of GDP for the United States and 175\% for Japan. Given the presence of large gross capital flows between the euro area and the rest of the world, it is important to consider the implications of financial trade by countries in the union with economies located outside of it, in order to conduct a comprehensive analysis of their pattern of external positions since the inception of the monetary union.

Distortions on asset holdings in the European Monetary Union. Several aspects of policy and regulation in the European Monetary Union are likely to have contributed to the pattern of intermediation of capital flows observed in the euro area. I will briefly discuss here some aspects of banking regulation and collateral eligibility rules in transactions with the European Central Bank that subsidized holdings of eurodenominated assets, for institutions based within the monetary union. In addition, I will review ex-post policy actions in the context of the sovereign debt crisis that, similarly to a bailout, reduced losses suffered by holders of peripheral countries' debt.

First, financial regulation in place in the EMU has provided incentives for banks in the euro area to hold large amounts of euro-denominated sovereign debt. In the European Union, the Capital Requirements Directive allowed financial institutions to assign a "zero-risk weight" to government debt of member states denominated and funded in own currency 12 According to Nouy (2012), the zero risk weight mandated by the Capital Requirements Directive, implied that local currency debt was largely regarded as risk-free by regulators. In addition, the author expressed a concern that banks were actively encouraged to accumulate sovereign debt by these aspects of regulation 13

Secondly, the ability to use sovereign debt issued by euro area governments as collateral in transactions with the European Central Bank has provided an additional incentive to financial institutions based in the monetary union in holding these assets. As suggested by Buiter and Sibert (2005), operational practices on collateral eligibility at the ECB have subsidized holdings by European banks of risky, short-maturity government debt. In particular, according to these authors, the eligibility as collateral of debt issued by all euro area governments has contributed to the compression of borrowing costs observed among euro area governments.

Third, actions taken by policy institutions in the euro area during the sovereign debt crisis, in the form of explicit bailouts or non-standard monetary policy, have contributed to reduce the adverse effects of the crisis on financial institutions with large exposures to peripheral governments. To the extent that banks in the euro area expected similar measures to be taken in the event of a crisis, such expectations induced them to exert less caution regarding the occurrence of future crises, as they expected, to some degree, to be

\footnotetext{
${ }^{12}$ Regulation (EU) No 575/2013, Part Three, Title II, Chapter 2, Section 2, Article 114.4 contains the most recent version of relevant legislation.

${ }^{13}$ Ms. Nouy was then General Secretary of the Prudential Supervisory Authority at the Banque de France. She is currently Chair of the Supervisory Board of the Single Supervisory Mechanism at the European Central Bank.
} 
bailed out in such circumstances 14 A concrete bailout example is reported by Acharya and Steffen (2013), who discuss the case of the Franco-Belgian banking group Dexia. The size of the sovereign bond portfolio of this institution amounted to "almost three times of its book equity", and it was largely composed of Italian and Greek government debt. In the second half of 2011, as sovereign bond prices fell and this bank found it harder to access sources of funding, Dexia was rescued by the governments of Belgium, France and Luxembourg. In addition, the Outright Monetary Transactions (OMT) programme launched by the ECB in 2012, with the aim of "safeguarding an appropriate monetary policy transmission and the singleness of the monetary policy", was successful in reducing yields on government debt of peripheral countries, thereby increasing the market value of such assets on financial institutions' balance sheets (Altavilla, Giannone and Lenza, 2014).

In the model presented in this paper, I introduce a bailout promise to represent institutional distortions giving preferential treatment to residents of an economic union when purchasing risky assets issued by union partners. This modelling choice allows me to characterize in a simple way a wide range of subsidies and distortions leading residents of an economic union to perceive returns on union-issued assets to be higher, or safer, than what perceived by outside residents 15

Trade integration and specialization. Trade with partners in the European Union accounted in 2005 for approximately two thirds of total trade by EU economies 16 Geographical proximity, similarity in tastes and explicit trade liberalization make it an unsurprising fact that European economies largely trade with each other, highlighting the high degree of goods market integration characterizing the Union.

Economies in the European Union, however, differ significantly in terms of relative specialization in those industries whose output is more extensively traded internationally. Manufacturing accounted in 2005 for $23 \%$ of Gross Value Added (GVA) in Germany, while representing only $10 \%$ and $16 \%$ of GVA in Greece and Spain, respectively 17 Peripheral economies, on the other hand, are relatively specialized in industries characterized by a lower degree of tradability of output. In the same year, construction accounted for only $4 \%$ of GVA in Germany, rising to $6 \%$ and $12 \%$ in Greece and Spain 18

In order to document the asymmetric pattern of specialization of European economies, accounting for heterogeneity in tradability of output produced by different industrial

\footnotetext{
${ }^{14}$ Acharya and Steffen (2013) document European banks' behavior of betting on the survival of the euro area, "choosing to hold peripheral sovereign bonds and financing their investments in short-term wholesale markets."

${ }^{15}$ Clearly, this assumption does not allow for a separate analysis of the individual channels suggested in the literature. Such analysis is left for future research.

${ }^{16}$ Source: Eurostat, International trade data.

${ }^{17}$ In the System of National Accounts, GVA "is defined as the value of output less the value of intermediate consumption and is a measure of the contribution to GDP made by an individual producer, industry or sector."

${ }^{18}$ Data are drawn from the OECD Structural Analysis (STAN) database.
} 
sectors, I construct a country-level measure of average tradability of output 19 I define tradability of individual industrial sectors as the ratio, for each sector, of total exports and imports attributed to that sector in a sample of advanced economies, to total Gross Value Added (GVA) of that sector. Formally, tradability of sector $s$ is defined as

$$
\operatorname{TDTY}_{s}=\frac{\sum_{i \in I} \operatorname{EXP}_{s, i}+\mathrm{IMP}_{s, i}}{\sum_{i \in I} \mathrm{GVA}_{s, i}}
$$

where $\mathrm{EXP}_{s, i}$ and $\mathrm{IMP}_{s, i}$ represent total exports and imports attributed to sector $s$ in country $i$. I represents the set of all countries in my sample. Hence, $\sum_{i \in I} \mathrm{GVA}_{s, i}$ represents total GVA of sector $s$ in the entire sample.

At country level, average tradability of output is given by the average of tradability in all industrial sectors, weighted by the shares of GVA represented by each sector in the economy of each country 20 Formally, this is given by

$$
\overline{\mathrm{TDTY}}_{i}=\sum_{s \in S} \mathrm{TDTY}_{s} \frac{\mathrm{GVA}_{s, i}}{\overline{\mathrm{GVA}}_{i}}
$$

where $S$ represents the set of all sectors that compose the economy and $\overline{\mathrm{GVA}}_{i}=\sum_{s \in S} \mathrm{GVA}_{s, i}$ represents total GVA in economy $i$.

Figure 3 presents values of average tradability of output for EU economies. Consistently with the observation that tradable sectors such as manufacturing are underrepresented in these economies, Greece, Spain and Portugal feature low average tradability of output. On the other hand, average tradability is high in Germany, especially in comparison to other very advanced economies. This variable, in fact, is closer in Germany to the level encountered in recent accession countries such as Hungary and Slovenia than in the United Kingdom or France. Low values for average tradability of output observed in Southern European economies are due to relative specialization in these countries towards those sectors characterized by lower sectoral tradability. Detailed evidence on EU economies' sectoral specialization is presented in Appendix A.1.

In the context of the model presented in the following section, I will study how specialization in industries characterized by lower tradability determines an amplification of the adverse effects of a debt crisis, when debt is owed to partners in an economic union. The ability of a country to generate trade surpluses through exports, in fact, is hampered by weak economic conditions in union partner economies if industrial specialization determines a high degree of exposure to export demand from these countries.

\section{A simple model of default, intermediation and trade}

This section presents a formal analysis of net and gross capital flows between countries in an economic union. I analyze, in particular, the implications on current account balances

\footnotetext{
${ }^{19} \mathrm{~A}$ complete description of the data used to construct this measure is presented in Appendix A.1.

${ }^{20}$ This measure is analogous to that of tradedness in Betts and Kehoe (2001).
} 


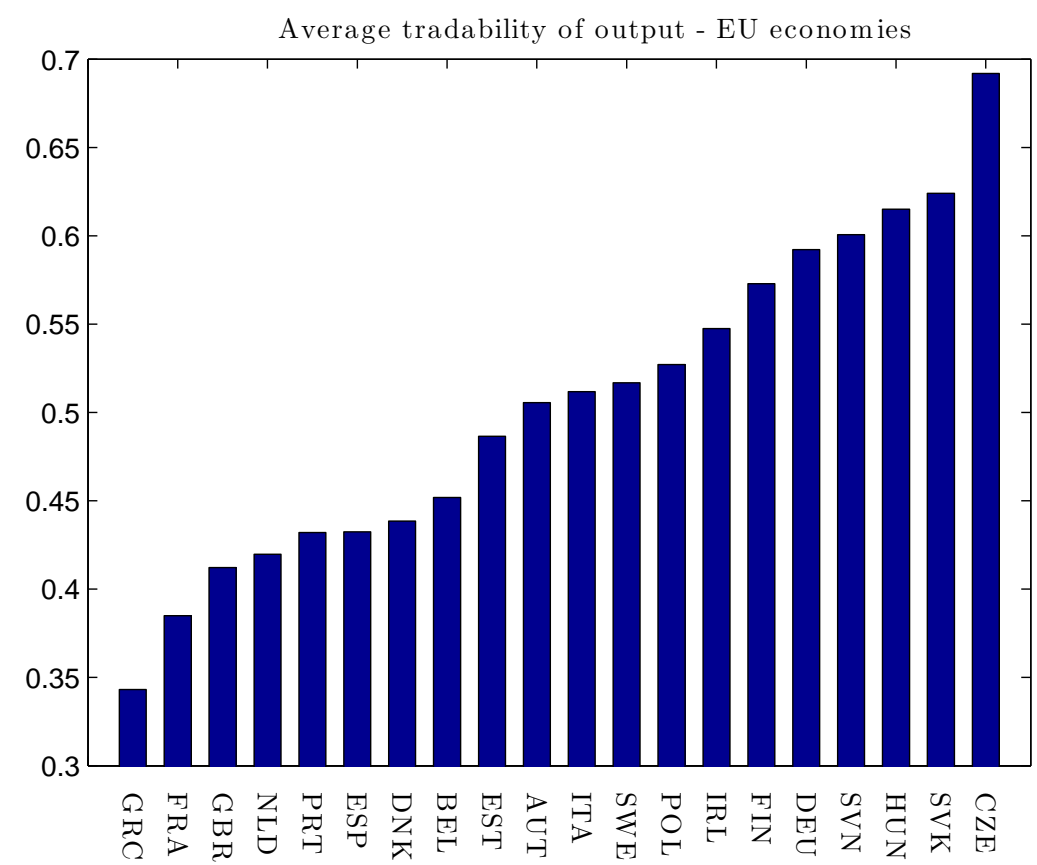

Figure 3: Average tradability of output in the European Union. This measure is computed as the weighted average of sector-level tradability of output, with weights given in each country by the shares of total GVA corresponding to each sector. Data source: OECD STAN and TiVA databases, year 2005.

and gross external positions of a subsidy on cross-border holdings of assets. In addition, I study under what conditions the interaction between trade integration and financial linkages introduced by the subsidy amplifies the severity of a debt crisis. Finally, I examine the rationale for the introduction of a subsidy on cross-border asset holdings, by assessing the implications of this distortion for welfare in the economic union. To this purpose, I introduce a simple model featuring trade in risky assets between two countries in an economic union and the rest of the world. To capture trade integration among members of an economic union, I introduce two types of consumption good, subject to heterogeneous transport costs across different country pairs 21

\subsection{Model}

Consider a two-period world economy. Time is discrete and indexed by $t \in\{1,2\}$. The world economy is inhabited by two small open economies, $H$ and $F$, and by the rest of the world, $R O W$. I will use the expression "economic union" when referring to the set of countries $H$ and $F$. All countries receive endowments of two types of consumption good,

\footnotetext{
${ }^{21}$ Appendix A.5 presents a one-good version of this model. Main results on current account imbalances and intermediation of gross capital flows will be present in that version as well. In addition, the onegood framework serves as a benchmark case to evaluate the effect in a crisis of trade integration among members of a union of countries.
} 
$A$ and $B$. Goods are tradable among all countries, subject to transport costs that are heterogeneous across country pairs and good types. All countries can issue one-period debt. $H$ is subject to a limited commitment friction, and it cannot promise to always repay external debt issued in the initial period. $F$ is not subject to limited commitment frictions 22 Households in $F$ enjoy a subsidy when purchasing $H$-issued assets, in the form of a bailout promise in the event of default by $H$. ROW is characterized as a large, risk-neutral agent.

Country H. $\quad H$ is inhabited by a continuum of identical households and by a benevolent fiscal authority. Lifetime utility of the representative household is given by:

$$
u\left(c_{1}\right)+\beta \mathbb{E}\left[u\left(c_{2}\right)\right]
$$

where $0<\beta<1$ is the subjective discount factor and $\mathbb{E}[\cdot]$ is the mathematical expectation operator. Consumption in each period is given by $c_{t}$. The period utility function, $u(\cdot)$, is increasing and concave. I will impose that $u(\cdot)$ takes a logarithmic form: $u(c)=\log (c)$. In each period, consumption of the representative household, $c_{t}$, is given by an aggregator of two consumption goods, $A$ and $B$ :

$$
c_{t}=\frac{\left(c_{A, t}\right)^{a}\left(c_{B, t}\right)^{1-a}}{a^{a}(1-a)^{1-a}} .
$$

The parameter $a \in(0,1)$ governs the utility weight of consumption good $A, c_{A, t} \cdot c_{B, t}$ denotes consumption by the representative household in $H$ of $\operatorname{good} B$. Good $A$ is the numéraire in the economy.

$H$ receives a constant stream of endowments of $\operatorname{good} B: y_{B, 1}=y_{B, 2}=y_{B}$. The stream of good $A$ received by $H$ is stochastic and its profile is skewed towards the terminal period:

$$
y_{A, 1}=y_{A}-\epsilon
$$

where $y_{A, 1}$ denotes initial-period endowment of good $A$ and $\epsilon>0$ represents the amount by which it falls short of a long-run value given by $y_{A}$. In the terminal period, $H$ faces income risk: it only receives the amount $y_{A}$ with probability $\pi$ and, with probability $1-\pi$, a lower amount $y_{A, L}<y_{A} 23$

$$
y_{A, 2}= \begin{cases}y_{A} & \text { w.p. } \pi \\ y_{A, L} & \text { w.p. } 1-\pi .\end{cases}
$$

Households in $H$ do not have access to financial markets. Their problem is simple: As they cannot trade in financial assets, they act as hand-to-mouth agents, consuming in

\footnotetext{
${ }^{22}$ This assumption, which is not essential, will be relaxed in the infinite-horizon model presented in Section 4.1, where all economies issue risky debt.

${ }^{23}$ I will limit attention to cases where the expected value of terminal-period resources is higher than the initial-period endowment: $y_{A, 1}<\mathbb{E}\left[y_{A, 2}\right]$.
} 
each period their endowment of both goods and net transfers they receive from the fiscal authority.

The fiscal authority in $H$ can issue debt on international financial markets in the initial period. Debt is denominated in units of numéraire, good $A$, and it is subject to a limited commitment friction. Bond holdings in $H$ are denoted by $b_{H}$, which takes negative values when the fiscal authority issues debt. In the terminal period, the fiscal authority can choose to default on its debt, suffering a default cost $\zeta$. The default cost takes the form of a reduction in the amount of good $A$ endowment. I assume that default costs are increasing in the realization of the endowment process 24 In particular, default costs are nil in the event of a low output realization and positive otherwise:

$$
\zeta= \begin{cases}0 & \text { if } y_{A, 2}=y_{A, L} \\ \hat{\zeta}>0 & \text { otherwise }\end{cases}
$$

The fiscal authority in $H$ maximizes welfare of the representative household, (1), by issuing debt in the initial period and choosing between default and repayment in the terminal period. Resources raised on international financial markets are rebated in lumpsum fashion to the representative household 25 Formally, the problem is given by:

$$
\begin{aligned}
V_{H}(\epsilon)= & \max _{\substack{b_{H}, c_{1}, c_{2}, D \in\{0,1\}}} u\left(c_{1}\right)+\beta \mathbb{E}\left[u\left(c_{2}\right)\right] \\
\text { s.t. } & p_{1} c_{1}+q_{H} b_{H}=y_{A}-\epsilon+p_{B, 1} y_{B}, \\
& p_{2} c_{2}=y_{A, 2}+p_{B, 2} y_{B}-\left[D \zeta-(1-D) b_{H}\right],
\end{aligned}
$$

All quantities are denominated in units of the numéraire good $A$. The relative price of good $B$ to good $A$ is denoted by $p_{B, t} . p_{t}$ is the price index of the consumption bundle $c_{t} 26$ The fiscal authority takes good prices as given. The amount of debt issued by $H$ in the initial period is given by $-b_{H}$, while $q_{H}$ denotes the price of a unit of debt. $D$ is an indicator taking value of unity in the event of default. The fiscal authority internalizes the effect of its choice for debt issued on the probability of terminal period default and on the debt price $q_{H}$.

Proceeding backwards from the terminal period, it is optimal for the fiscal authority to repay debt when $-b_{H} \leq \zeta$. When debt is positive, default occurs in the event of a low output realization, which is accompanied by the absence of default costs. Default would occur with certainty if debt were to be higher than the upper bound of default costs, $\hat{\zeta}$. The following proposition establishes optimality, from the point of view of the fiscal authority in $H$, of issuing debt carrying positive but not certain default probability:

\footnotetext{
${ }^{24}$ This is a common assumption in the endogenous sovereign default literature. Mendoza and Yue (2012) study how frictions in markets for imported inputs give rise to endogenous default costs that are increasing in TFP.

${ }^{25}$ The choice for initial-period debt determines, from the budget constraint, plans for initial and terminal-period consumption of the representative household.

${ }^{26}$ Given intratemporal preferences, the price index of the consumption bundle is given in each period by $p=\left(p_{B}\right)^{1-a}$.
} 
Proposition 1. H's optimal choice for $b_{H}$ lies in the interval $[-\hat{\zeta}, 0)$ for a sufficiently low realization of the initial-period good $A$ endowment, $y_{A}-\epsilon$, given values for $y_{A, L}, \pi$, and $\beta$.

Proof. See appendix A.2,

Given this choice, as default in the terminal period only occurs in the event of a low output realization, the probability of terminal-period default is given by $1-\pi$. The solution to the problem of the fiscal authority can be summarized by the optimality condition:

$$
q_{H} \frac{u^{\prime}\left(c_{1}\right)}{p_{1}}=\beta \pi \frac{u^{\prime}\left(c_{2, R}\right)}{p_{2, R}} .
$$

where $p_{2, R}$ and $c_{2, R}$ denote the price index and consumption by $H$, respectively, in the terminal-period state of the world where repayment is optimal. The benefit of issuing a marginal unit of debt is equal to its marginal cost, at an optimum. The cost of repaying debt in the terminal period is only borne by the representative household in the state of the world where it is optimal not to default. Finally, demand for the two individual goods is given in each period by:

$$
c_{A}=a p c \text { and } c_{B}=(1-a) \frac{p}{p_{B}} c .
$$

Country F. As is country $H, F$ is inhabited by a continuum of identical households. Preferences of households in $F$ are identical to those of households in $H$, as defined in (2) and (11). Variables pertaining to country $F$ are indexed by an asterisk, so that $c_{t}^{*}, c_{A, t}^{*}$ and $c_{B, t}^{*}$ indicate aggregate consumption and consumption of the two types of good by the representative household in country $F$ in period $t$.

Households in $F$ can trade assets on international financial markets in the initial period. In particular, households in $F$ can issue risk-free debt $b_{F}$ to $R O W$ and purchase assets issued by $H$. Again, all assets are denominated in units of numéraire good $A$.

$F$-households are promised by their domestic fiscal authority that they will be bailed out of losses incurred on assets issued by $H$ in the event of its default. The extent of partial bailout offered to households in $F$ is captured by the parameter $\xi \in[0,1]$. Individual households have full information on the state variables determining the solution to the problem in $H$, (5) , and they correctly understand what is the optimal default policy by $H$. Due to the presence of the bailout promise, the return on an asset issued by $H$ in the event of default, as perceived by a resident of $F$, is equal to $\xi$. Absent a bailout promise, the return on debt issued by $H$ in the event of default would be zero 27 In the event of default by $H$, bailout transfers received by individual households in $F$ are financed by a lump-sum $\operatorname{tax} T$ on all households in the country. Consumption of the representative

\footnotetext{
${ }^{27}$ I restrict the bailout promise $\xi$ to take a value of zero if $-b_{H}>\hat{\zeta}$. Absent this restriction, a positive price for $b_{H}$ would be bid by households in $F$ even when default would occur with certainty. The problem faced by the fiscal authority in $H$ would not have a finite solution, as the choice of debt issued by $H$ would be unbounded.
} 
household in the terminal period then fully bears the negative wealth shock implied by default of $H$. Each individual household, however, perceives that it will be bailed out of any losses on its bond holdings.

The problem solved by the representative household in $F$ in the initial period is the following:

$$
\begin{aligned}
V_{F}(\epsilon)= & \max _{\substack{c_{1}^{*}, c_{2}^{*}, b_{F}, b_{H F} \geq 0}} u\left(c_{1}^{*}\right)+\beta \mathbb{E}\left[u\left(c_{2}^{*}\right)\right] \\
\text { s.t. } & p_{1} c_{1}^{*}+q_{F} b_{F}+q_{H} b_{H F}=y_{A}^{*}+p_{B, 1} y_{B}^{*}, \\
& p_{2} c_{2}^{*}=y_{A}^{*}+p_{B, 2} y_{B}^{*}+b_{F}+\left[D\left(\xi b_{H F}-T\right)+(1-D) b_{H F}\right],
\end{aligned}
$$

The amount of $H$-issued assets purchased by the representative household in $F$ is denoted by $b_{H F}$. Liabilities issued to $R O W$ at price $q_{F}$ are denoted by $-b_{F}$. The representative household in $F$ acts as a price taker with respect to good prices. Debt prices $q_{H}$ and $q_{F}$ are also taken as given, as is the value of the lump-sum tax $T$. In equilibrium, tax receipts finance bailout payments in the default state of the world, $T=\xi b_{H F}$.

Restricting attention to cases where $H$ issues risky debt and gross assets purchased by $F$ are positive, $b_{H} \in(-\hat{\zeta}, 0)$ and $b_{H F}>0$, the solution to the problem in $F$ can be summarized by the following system of first-order conditions:

$$
\begin{aligned}
& q_{F} \frac{u^{\prime}\left(c_{1}^{*}\right)}{p_{1}}=\beta \mathbb{E}\left[\frac{u^{\prime}\left(c_{2}^{*}\right)}{p_{2}}\right] \\
& q_{H}=q_{F}-\beta(1-\pi)(1-\xi) \frac{u^{\prime}\left(c_{2, D}^{*}\right) / p_{2, D}}{u^{\prime}\left(c_{1}^{*}\right) / p_{1}} .
\end{aligned}
$$

The subscript $D$ denotes the terminal-period state of the world where default by $H$ is optimal and, again, $R$ denotes the one where repayment is preferred. The first equation is standard and it simply describes the optimal intertemporal allocation of consumption by $F$. The second equation characterizes the price $q_{H}$ at which households in $F$ are willing to purchase a positive amount of $H$-issued assets. $F$-households need to be compensated for default risk, given by the probability of default times the loss suffered on each unit of asset: $(1-\pi)(1-\xi)$. In addition, households need to be compensated for volatility in terminalperiod consumption that default risk induces, as captured by the term $\frac{u^{\prime}\left(c_{2, D}^{*}\right) / p_{2, D}}{u^{\prime}\left(c_{1}^{*}\right) / p_{1}}$. Note that if a full bailout promise is offered, $\xi=1$, the price that $F$-households are willng to bid for $H$-issued assets equals the one of risk-free liabilities, $q_{F}$. This is the same price they would bid on truly risk-free assets, if $\pi=1$.

Finally, demand functions for individual goods are determined as in $H$ :

$$
c_{A}^{*}=a p c^{*} \text { and } c_{B}^{*}=(1-a) \frac{p}{p_{B}} c^{*} .
$$

ROW. The representative household in $R O W$ has risk-neutral preferences over consumption. Its intratemporal preferences are identical to those in $H$ and $F$, as is its 
discount factor, $\beta$. The economy in $R O W$ is large when compared to $H$ and $F$. In particular, endowments of either good in $H$ and $F$ are of negligible size when compared to those in $R O W$. As in country $F$, the stream of endowments received by $R O W$ is deterministic and constant: $y_{A, 1}^{R O W}=y_{A, 2}^{R O W}=y_{A}^{R O W}, y_{B, 1}^{R O W}=y_{B, 2}^{R O W}=y_{B}^{R O W}$. Bond holdings by $R O W$ of risk-free assets are given by $b_{R O W}$. The price of a risk-free asset issued by $R O W$ is given by $q_{R O W}$. Bond holdings by $R O W$ of $H$-issued assets are given by $b_{H, R O W} 28$

Transport costs. Good $A$ can be costlessly traded across all country pairs. International trade of good $B$ is subject to an iceberg transport cost $\tau$ that only applies to trade with $R O W$ : For each unit of good $B$ that is shipped by an exporter, only $1-\tau$ units are received by the destination country. Absence of transport costs affecting trade between $H$ and $F$ captures strong goods market integration among members of an economic union. Heterogeneous transport costs affecting goods $A$ and $B$ serve instead as a proxy for heterogeneous tradability of output of different industrial sectors. In the model, countries that are relatively abundant in good $B$ describe economies that are characterized by low average tradability of output. Relative abundance of the two types of good in $H$ and $F$ is captured by the ratios $\frac{y_{A}}{y_{B}}$ and $\frac{y_{A}^{*}}{y_{B}^{*}}$.

The relative price of good $B$ to good $A$ prevailing in $H$ and $F$ can be interpreted as the terms of trade of the country that is relatively abundant in good $B$. Due to the presence of transport costs, good prices in $R O W$ may differ from those prevailing in the union formed by $H$ and $F$. The relative price of good $B$ to good $A$ in $R O W$ is denoted by $p_{B}^{R O W}$.

World prices. In equilibrium, world prices follow from the solution of $R O W$ 's problem, given the negligible size of $H$ and $F$ compared to the world economy. The world price of a risk-free bond is given by $q_{R O W}=\beta$, by risk-neutrality of $R O W 29$ Bonds issued by $F$ are risk-free, so that their price is also given by

$$
q_{F}=q_{R O W}=\beta .
$$

If $R O W$ holds a positive amount of bond issued by $H$, the price of this asset must compensate $R O W$ for default risk. Hence, $b_{H, R O W}>0$ implies

$$
q_{H}=\beta \mathbb{E}[1-D] .
$$

In particular, if $b_{H} \in(-\hat{\zeta}, 0)$, the probability of repayment is given by $\pi$ and $q_{H}=\beta \pi$. $R O W$ is not willing to buy assets issued by $H$ if $q_{H}>\beta \mathbb{E}[1-D]$. In this event, $F$ would be the marginal and sole buyer of assets issued by $H: b_{H, R O W}=0$ and, by market clearing, $b_{H F}=-b_{H}$.

\footnotetext{
${ }^{28}$ The optimization problem solved by $R O W$ is described in detail in Appendix A.3,

${ }^{29}$ Since assets are denominated in units of numeraire good $A$, the first order condition in $R O W$ implies $q_{R O W}=\beta \frac{p_{1}^{R O W}}{p_{2}^{R O W}}$. Given the constant endowment streams, $p_{1}^{R O W}=p_{2}^{R O W}$, so that $q_{R O W}=\beta$ holds.
} 
World good prices are also determined in $R O W$. When $H$ or $F$ export good $B$ to $R O W$, arbitrage and transport costs imply $p_{B}=(1-\tau) p_{B}^{R O W}$. Symmetrically, when $R O W$ exports good $B$ to either $H$ or $F, p_{B}=\frac{1}{(1-\tau)} p_{B}^{R O W}$. Finally, when $\tau>0$, a no-trade equilibrium can arise, where price differentials are too small, compared to transport costs, for intratemporal trade in $B$ to emerge. Indeed, when $p_{B} \in\left((1-\tau) p_{B}^{R O W}, \frac{1}{(1-\tau)} p_{B}^{R O W}\right)$, no trade in good $B$ takes place between $H$ or $F$ and $R O W$. When trade in good $B$ between $H, F$ and $R O W$ does not take place, the markets for good $B$ in $H$ and $F$ and in $R O W$ have to individually clear:

$$
y_{B}+y_{B}^{*}=c_{B, s}+c_{B, s}^{*} \text { and } y_{B}^{R O W}=c_{B, s}^{R O W} .
$$

Demand for good $B$ by $H$ and $F$ is then satisfied entirely by supply within these countries. Within this interval, the relative price of good $B$ in $H$ and $F$ is determined by market clearing within the economic union. From intratemporal preferences, this relative price is given by 30

$$
p_{B}=\frac{1-a}{a} \frac{c_{A}+c_{A}^{*}}{c_{B}+c_{B}^{*}}=\frac{1-a}{a} \frac{c_{A}+c_{A}^{*}}{y_{B}+y_{B}^{*}}
$$

Equilibrium. I will now proceed to define a competitive equilibrium in the world economy.

Definition 1. An equilibrium is defined as a vector of quantities $b_{H}, b_{H F}, b_{F}, b_{R O W}$, $b_{H, R O W}, c_{s}, c_{A, s}, c_{B, s}, c_{s}^{*}, c_{A, s}^{*}, c_{B, s}^{*}, c_{s}^{R O W}, c_{A, s}^{R O W}, c_{B, s}^{R O W}$, prices $q_{H}, q_{F}, q_{R O W}, p_{B, s}, p_{s}$, $p_{B, s}^{R O W}, p_{s}^{R O W}$ and default indicator $D$ such that, given values for the bailout promise $\xi$, transport costs $\tau$ and output realization $\epsilon$, in all time periods and states of the world, as indexed by $s \in\{1 ; 2, R ; 2, D\}$ :

- $b_{H}$ and $\left\{c_{s}\right\}_{s}$ solve the intertemporal allocation problem in $H$, (5), given $q_{H}$ and $\left\{p_{s}\right\}_{s}$.

- D solves optimal default policy by $H$, as defined by (5).

- $b_{F}, b_{H F}$ and $\left\{c_{s}^{*}\right\}_{s}$ solve the intertemporal allocation problem in $F$, (8), given $q_{F}$, $q_{H}$ and $\left\{p_{s}\right\}_{s}$.

- $\left\{c_{A, s}, c_{A, s}^{*}, c_{B, s}, c_{B, s}^{*}\right\}_{s}$ solve demand for individual goods by $H$ and $F$, (77) and (10), given $\left\{c_{s}, c_{s}^{*}\right\}_{s}$ and prices $\left\{p_{B, s}, p_{s}\right\}_{s}$.

- $b_{R O W}, b_{H, R O W}$ and $\left\{c_{s}^{R O W}\right\}_{s}$ solve the intertemporal allocation problem in $R O W$ given $q_{R O W}, q_{H}$ and $\left\{p_{s}^{R O W}\right\}_{s} \cdot\left\{c_{A, s}^{R O W}, c_{B, s}^{R O W}\right\}_{s}$ satisfy $R O W$ 's demand for individual goods, given $\left\{c_{s}^{R O W}\right\}_{s}$ and prices $\left\{p_{B, s}^{R O W}, p_{s}^{R O W}\right\}_{s}$.

- All markets for assets clear:

$$
\begin{aligned}
& 0=b_{H}+b_{H F}+b_{H, R O W} \\
& 0=b_{F}+b_{R O W}
\end{aligned}
$$

${ }^{30}$ From (7) and (10), it can be seen that $c_{A}+c_{A}^{*}=\frac{a}{1-a} \frac{c_{B}+c_{B}^{*}}{p_{B}}$. 
- The world market for good B clears, net of resources lost to transport costs between $H, F$ and $R O W$ :

$$
y_{B}+y_{B}^{*}+y_{B}^{R O W}=c_{B, s}+c_{B, s}^{*}+c_{B, s}^{R O W}+\tau\left|y_{B}^{R O W}-c_{B, s}^{R O W}\right|
$$

- The market for good A clears by Walras' law.

$$
c_{A, s}+c_{A, s}^{*}+c_{A, s}^{R O W}=y_{A, s}+y_{A}^{*}+y_{A}^{R O W}
$$

\subsection{Results}

Intermediation and gross capital flows. What drives intermediation of international capital flows in this framework? When is it optimal for an economy like $F$ to be the main holder of risky debt issued by its partner in the economic union? Risk aversion and the presence of a bailout promise play a crucial role in answering these questions.

In the absence of a bailout promise, risk-averse households in $F$ are not willing to be the marginal buyers of debt issued by $H$. From $F$ 's Euler equation, (9), the price consistent with $H$-assets being priced by $F$-households is given by

$$
q_{H, F}=\beta\left[1-(1-\pi) \frac{u^{\prime}\left(c_{2, D}^{*}\right) / p_{2, D}}{u^{\prime}\left(c_{1}^{*}\right) / p_{1}}\right],
$$

where $q_{F}=\beta$ follows from (11), as assets issued by $F$ are risk-free. Due to risk-aversion in preferences of $F$, (1), this price is lower than the one consistent with pricing by $R O W$, $q_{H, R O W}=\beta \pi$.

$$
\frac{u^{\prime}\left(c_{2, D}^{*}\right) / p_{2, D}}{u^{\prime}\left(c_{1}^{*}\right) / p_{1}}>1
$$

$F$ would suffer from low consumption in the state of the world where $H$ defaults, if it were a holder of $H$-issued assets. $F$-households have to be compensated for this risk, whose price is captured by the ratio of marginal utilities across initial and terminal periods. Hence, given its risk-neutrality, $R O W$ is the marginal buyer of assets issued by $H$, in the case where households in $F$ are not offered a bailout promise on these assets. 31

When a full bailout promise is offered, $H$-issued assets are perceived as risk-free by $F$-households. Accordingly, they are willing to purchase these assets at a price equal to that of risk-free liabilities:

$$
q_{H, F}=q_{F}=\beta .
$$

To the extent that these assets are not truly risk-free, $\pi<1$, the price bid by $H$ is not sufficiently high to compensate $R O W$ for default risk, $\beta>\beta \pi$, and $R O W$ will not

\footnotetext{
${ }^{31}$ In an equilibrium where $\frac{p_{2, D}}{p_{1}}$ is sufficiently high, it would be optimal for $F$ to hold the entire amount of $H$-issued debt even in the absence of bailout promise, in order to transfer resources across states of the world and exploit differences in good prices. This equilibrium, however, would only arise in the presence of severe transport costs, and it is ignored here.
} 
buy any positive amount of $H$-issued debt. The entire debt issued by $H$ is then held in equilibrium by $F$.

Gross asset purchases by $F$ are partly financed with own resources, as well as by intermediating funds borrowed from $R O W$. The fraction of gross asset purchases that $F$ finances by issuing gross liabilities lies in the interval 32

$$
\frac{b_{F}}{b_{H}} \in\left(\frac{\beta}{1+\beta}, 1\right] \text { for } \pi \in(0,1]
$$

Three main results emerge on intermediation of gross capital flows by $F$. First, if repayment by $H$ is certain, $F$ entirely finances its purchase of $H$-debt by borrowing from $R O W, b_{F}=b_{H}$. As debt issued by $H$ is truly risk-free, the bailout promise has no effect on the equilibrium allocation: $F$ fully intermediates gross asset purchases by issuing gross liabilities, and the allocation is equal to one where debt issued by $H$ is held directly by $R O W$. Second, in the limit where default by $H$ is certain, $\pi \rightarrow 0, F$ is a net saver and its gross liabilities are smaller in magnitude than gross assets, $\lim _{\pi \rightarrow 0} b_{F}=\frac{\beta}{1+\beta} b_{H}$. Households in $F$ face positive taxes with certainty in the terminal-period, to cover for certain losses on gross assets 33 Hence, they act as net savers, in order to transfer resources to the terminal period and mitigate the fall in consumption following default by $H$. Finally, when the terminal-period repayment is uncertain, $\pi \in(0,1)$, households in $F$ face uncertainty with regard to terminal-period taxation and consumption. The larger is the magnitude of consumption risk, the more $F$ households will save to insure against it. Hence, the fraction of gross asset purchases that is financed with own resources is increasing in the relative size of gross assets to terminal-period endowment. The optimal amount of gross liabilities issued by $F$ is presented graphically in Figure 4, for values of $\pi \in(0,1]$ and for two different relative values of gross assets to total endowment.

Debt crisis in an economic union. Motivated by recent experience in the euro area, we can employ the model here presented to study the transmission and amplification of a debt crisis taking place in an economic union. A crucial role is played in this setting by the interaction between trade integration and financial linkages characterizing countries in the economic union.

I analyze consumption by $H$ and $F$ in the terminal-period crisis state, where $H$ faces a low output realization, $y_{A}=y_{A, L}$, and it does not repay its debt. By comparing the equilibrium allocation with bailout promise to the one with no bailout, we are able to analyze how policy distortions in the economic union lead to cross-border transmission and amplification of a debt crisis 34

\footnotetext{
${ }^{32}$ This result follows from the solution to the system of optimality conditions in (9). I consider here for simplicity a setup where $\tau=0$, so that good prices are constant across states of the world as determined in $R O W$, and normalized to unity. I define total endowment in $F$ as $y^{*}=y_{A}^{*}+y_{B}^{*}$.

${ }^{33}$ Note that while individual households do not internalize the effects of their choices on taxation, in equilibrium, they correctly form expectations on terminal-period taxation, $T=\xi b_{H F}$.

${ }^{34}$ When discussing crisis transmission and amplification, it is worth noting that endowment realizations are not affected by features of the equilibrium of this economy, them being exogenous. However,
} 


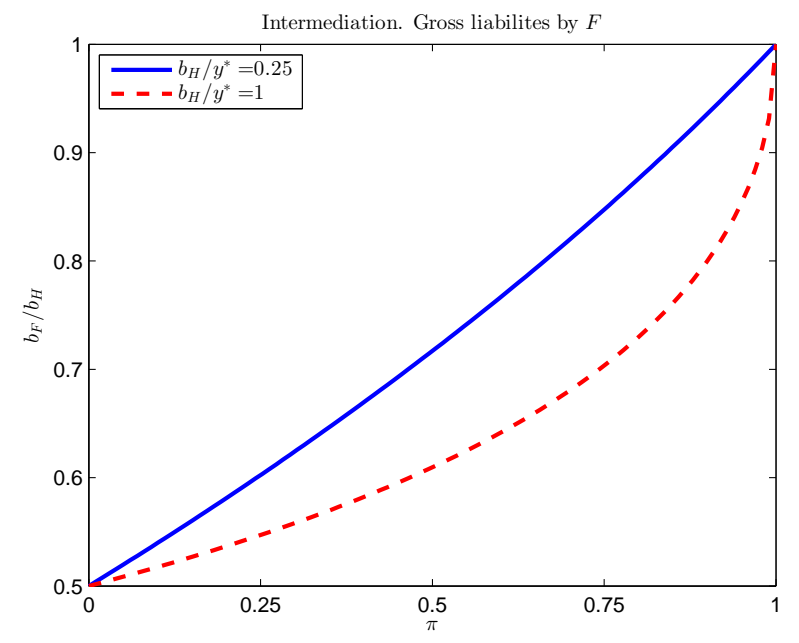

Figure 4: Issuance of gross liabilities by $F$ as function of repayment probability by $H$ and size of gross assets. The blue, solid line represents the fraction of gross assets purchased by $F$ that is financed by borrowing from $R O W$, for a low amount of gross assets relative to total income, $b_{H} / y^{*}=.25$. The red, dashed line represents the same variable for a higher ratio of gross assets to income, $b_{H} / y^{*}=1$.

The introduction of a bailout promise generates financial linkages between members of the economic union, through which a crisis is transmitted from debtors to creditors. This policy distortion induces $F$ to take on exposure to default risk by $H$, issuing debt to finance asset purchases. In the crisis state, wealth in $F$ is lower when this country intermediates resources towards $H$, as gross assets give no return and gross liabilities to $R O W$ are repaid. Formally, aggregate consumption by $F$ in the terminal-period crisis state is given by:

$$
c_{2, D}^{*}=\left(y_{A}^{*}+p_{B} y_{B}^{*}+b_{F}\right) \frac{1}{p}
$$

To the extent that $F$ issues a positive amount of gross liabilities in order to purchase assets issued by $H$, policy distortions cause consumption in this country to be lower in the crisis state. The mismatch between risky gross assets and safe gross liabilities on F's external balance sheet leads to a transmission of the crisis to this country, with detrimental effects on consumption.

Amplification of the crisis in the debtor country arises when creditors on its external liabilities coincide with the destination of its exports. In the crisis state, $H$ is reduced to financial autarky, but it is able to trade in goods $A$ and $B$, according to relative abundance of the two in its endowment basket. Aggregate consumption by $H$ in the crisis then crucially depends on the relative price of its exports. When transport costs imply that good $B$ is not traded with $R O W$, its relative price is function of relative abundance within the union of $H$ and $F$. In the crisis state, the relative price $p_{B}$ is

endowment values in terms of consumption good are endogenous, due to the possibility of changes in goods relative prices, representing the terms of trade of countries in the economic union. 
determined according to (13):

$$
p_{B}=\frac{1-a}{a} \frac{c_{A, 2, D}+c_{A, 2, D}^{*}}{c_{B, 2, D}+c_{B, 2, D}^{*}}=\frac{1-a}{a} \frac{y_{A, L}+y_{A}^{*}+b_{F}}{y_{B}+y_{B}^{*}}
$$

Intermediation of gross flows by $F$ causes the relative price of good $B$ to be lower in the crisis state. The bailout promise induces $F$ to issue gross liabilities to $R O W, b_{F}<0$. In the crisis state, the amount of good $A$ available in the union is then lower than it would be had $H$ borrowed directly from $R O W$, and defaulted on its liabilities. In turn, in the crisis state, relative scarcity of $A$ causes the price $p_{B}$ to be lower than it would be, had $F$ not acted as an intermediary between $H$ and $R O W$.

The effect of lower union wealth on the crisis country, $H$, depends on the status of this country as a net exporter or importer of the good subject to transport costs, $B$. Denote by $p_{B, I}$ the crisis-state relative price of good $B$ in the equilibrium allocation where, due to the presence of a bailout promise, external borrowing by $H$ is intermediated by $F$. Denote by $p_{B, N I}$ the relative price in the equilibrium where no bailout is promised, no intermediation occurs, and $H$ borrows directly from $R O W$. As gross liabilities issued by $F$ are higher in the equilibrium allocation with bailout, (13) implies $p_{B, I}<p_{B, N I}$.

Consider now two extreme cases of full specialization by $H$. First, when $H$ is fully specialized in good $B, y_{A, L}=0, y_{B}>0$, it can be shown that its relative consumption across the two equilibrium allocations is proportional to the relative difference in $p_{B}$ :

$$
\frac{c_{I}}{c_{N I}}=\left(\frac{p_{B, I}}{p_{B, N I}}\right)^{a} .
$$

Second, and conversely, if $H$ is fully specialized in good $A$, its relative consumption is inversely related to the difference in $p_{B}$ :

$$
\frac{c_{I}}{c_{N I}}=\left(\frac{p_{B, I}}{p_{B, N I}}\right)^{a-1},
$$

as $a-1<0$. Finally, when relative abundance of the two goods in $B$ equals relative abundance in the union, the fall in $p_{B}$ has no effect on consumption, as no intra-temporal trade occurs. Formally, $c_{I}=c_{N I}$ if

$$
\frac{y_{B}}{y_{B}+y_{B}^{*}}=\frac{y_{A}}{y_{A, L}+y_{A}^{*}+b_{F, N I}}
$$

with $c_{I}<c_{N I}$ for values of $\frac{y_{B}}{y_{B}+y_{B}^{*}}$ above this threshold and vice versa 35 The higher the share of good $B$ in the endowment basket of $H$, the more severe is the crisis in this country. Amplification occurs as demand in export destinations deteriorates in the event of the crisis, due to the presence of financial linkages between trade partners. If the crisis

\footnotetext{
${ }^{35}$ The result in (17) holds locally, for $\frac{p_{B, I}}{p_{B, N I}} \approx 1$. A full derivation of results in this section is provided in Appendix A.4.
} 
country were instead a net exporter of good $A$, it would benefit from cheaper imports of good $B$, while being able to export to $R O W$ which is unaffected by the crisis.

Prior to the euro area sovereign debt crisis, Greece, Spain and Portugal were relatively specialized in sectors characterized by lower tradability of output, as detailed in Section 2. To the extent that lower output tradability implied stronger trade linkages with partners in the monetary union, this mechanism may have played a role in exacerbating the recession observed in the periphery of the euro area during the recent crisis. I present in Section 4 a quantitative evaluation of these channels, in the context of an infinitehorizon framework.

Optimal bailout promise. In order to analyze the rationale behind the introduction of distortions on cross-border holdings of assets, I discuss here conditions under which it is optimal, from the point of view of a union-wide benevolent planner, to introduce a bailout promise on risky assets. In an environment characterized by the presence of frictions that prevent the equilibrium allocation from being Pareto optimal, it need not be the case that the introduction of an additional distortion diminishes welfare 36 In this framework, such frictions are represented by the inability of the fiscal authority in $H$ to commit to repay debt in the terminal-period crisis state. There indeed exist equilibrium allocations in this model where aggregate welfare in the economic union with a full bailout promise is higher than that attained absent such a distortion. The introduction of a bailout promise distorts the allocation in $F$, inducing excessive risk-taking and leverage. In country $H$, subject to the limited commitment friction, the same distortion determines a higher price of debt issued, allowing for additional borrowing. When borrowing frictions are sufficiently severe, due for example to scarce initial-period resources in $H$, the benefits of redistribution would outweigh the costs of distortion, making a bailout promise desirable.

Consider welfare in the union as the sum of welfare in the two countries, as function of the initial period income shock in $H, \epsilon$ :

$$
V(\epsilon)=V_{H}(\epsilon)+V_{F}(\epsilon)
$$

We are interested in studying the change in aggregate welfare when comparing an allocation with no bailout promise, $\xi=0$, to another one with bailout, e.g. $\xi=1$. It is possible to analytically compare welfare in the union across these two different allocations by focusing on the limiting case where $\pi$, the probability of repayment by $H$, tends to zero 37 Absent a bailout promise, neither $H$ nor $F$ would engage in financial trade, for opposite reasons. The flat endowment profile in $F$ ensures that this country achieves in financial autarky the optimal allocation of consumption across periods and states, so that no borrowing or lending takes place:

$$
c_{1}^{*}=c_{2}^{*}=y^{*} .
$$

\footnotetext{
${ }^{36}$ A canonical reference is Lipsey and Lancaster (1956).

${ }^{37} \mathrm{As}$ in the previous discussion on intermediation, I am considering here an allocation with no transport costs and constant good prices determined by $R O W$. As prices are constant, I am also ignoring endowments of the two different goods and focusing simply on total endowments $y$ and $y^{*}$.
} 
Scarcity of initial period resources, implies instead the presence of a borrowing motive in $H$. It cannot borrow if default is certain, however, as debt is issued at price $q_{H}=\beta \pi=0$. The lower the initial period endowment, then, the higher is marginal utility of initialperiod consumption in $H$ and the more skewed will be the consumption profile in this country:

$$
c_{1}=y-\epsilon, c_{2, D}=y_{L}, c_{2, R}=y
$$

When a bailout promise is offered, default by $H$ still occurs with certainty, as $\pi \rightarrow$ 0 , but $F$ is now willing to lend, financing asset purchases with own resources and by borrowing from $R O W$. Lending simply amounts to a free transfer of resources to $H$, so that wealth in $F$ falls as consequence of the bailout distortion. $H$ receives resources in the initial period, when they are the most needed, and its welfare rises in this allocation 38 Importantly, the welfare gain in $H$ is increasing in the initial period shock, $\epsilon$, by concavity of the utility function. Hence, as welfare in $F$ is unaffected by $\epsilon$ in either the full or nobailout promise allocations, the following result can be established:

Proposition 2. For a sufficiently high value $\bar{\epsilon}$ of the initial period shock $\epsilon$, an allocation with bailout promise, $\xi=1$ delivers aggregate welfare $V(\epsilon)$ that is equivalent to that attained in the allocation where no bailout is promised, $\xi=0$. The bailout promise allocation is preferable to the no-bailout one for values of $\epsilon$ above that threshold.

Proof. See appendix A.6.

Intuitively, the bailout distortion allows resources to be transferred across members of the union. This transfer, however, is only desirable if resources in the destination country are sufficiently scarce.

The above result on optimality of bailout promises can help to shed light on the rationale for the introduction of similar distortions in the euro area. At the cost of generating critical financial linkages, implicit subsidies on cross-border asset holdings may have contributed to a relaxation of borrowing limits faced by peripheral countries. The relaxation of such constraints could have been seen as desirable, in turn, if relative incomes in these countries were expected to converge.

\section{An infinite-horizon model of gross capital flows and debt crises}

I introduce in this section a quantitative model of countries in an economic union, trading among each other and with the rest of the world in goods and financial assets. The purpose of the model is to quantitatively assess the ability of policy distortions on financial trade in a union to explain the recent European experience in terms of capital flows.

\footnotetext{
${ }^{38}$ The amount of borrowing by $H$ is bounded above by the amount of resources available in the repayment state, as except in the limit $\pi>0$ holds, and marginal utility of consumption would otherwise be unbounded if $H$ had to repay debt.
} 
In the model, the introduction of a subsidy on cross-border holdings of assets in an economic union generates predictions for current account and gross external positions that are in line with empirical evidence for the euro area. In addition, the model predicts that countries with substantial external liabilities are more severely affected by a debt crisis when their creditor countries coincide with the main destination of their exports.

The next subsection presents the infinite-horizon model. Two model economies are considered, characterized by different treatment of risky assets within the economic union. Thereafter, I present the calibration of the model to properties of euro area countries prior to the inception of the EMU and I describe the steady state allocation. Finally, I present results of the two quantitative experiments I consider. First, I consider the dynamic transition of the model economy after the introduction of subsidies on risky assets in the economic union. I analyze, in particular, the implications of this change on current account imbalances and on intermediation within the union of gross capital flows from the rest of the world. Second, I analyze a debt crisis, describing its transmission and amplification via financial and trade linkages among member countries of an economic union.

\subsection{Infinite-horizon model}

Environment. The world economy is inhabited by a continuum of unit measure of small open economies, $I$, and by the rest of the world, $R O W$. The small open economies in $I$ will be referred to as countries and they are indexed by $i \in[0,1]$. Each country is inhabited by a continuum of identical households. Time is discrete and indexed by $t$. There are two types of goods, $A$ and $B$. Good $A$ is freely tradable across all country pairs, while trade in good $B$ between $R O W$ and countries in $I$ is subject to an iceberg transport cost $\tau$ Each country in $I$ receives a stream of endowments of either type of good. $F=[0, \kappa]$ denotes the subset of countries in $I$ that receive endowments of good $A$, while countries in the complementary set, $H=(\kappa, 1]$, receive endowments of good $B$. Good $A$ is the numeraire in the world economy. Each country receives a stream of endowments $\left\{y_{i, t}\right\}_{t=0}^{\infty}$ which is determined according to a stochastic Markov process. The process is i.i.d. across countries and there is no aggregate uncertainty in the world economy.

Households in each country $i$ enjoy consumption of both types of good. Preferences of the representative household over consumption paths are indexed according to:

$$
U_{i}=\mathbb{E}_{0} \sum_{t=0}^{\infty} \beta^{t} u\left(c_{i, t}\right),
$$

where $\mathbb{E}_{0}$ is the mathematical expectation operator conditional on information available at time zero, $\beta$ is the subjective discount fator and $c_{i, t}$ denotes aggregate consumption in $i$. The period utility function takes the CRRA form $u(c)=\frac{c^{1-\gamma}}{1-\gamma}$, where the parameter $\gamma$

\footnotetext{
${ }^{39}$ This assumption on heterogeneous transport costs is the same one made in the model of Section 3.
} 
captures the degree of relative risk aversion. In each period, aggregate consumption by the representative household is defined as the CES aggregator:

$$
c_{i}=\left[a^{\frac{1}{\vartheta}} c_{A, i}^{\frac{\vartheta-1}{\vartheta}}+(1-a)^{\frac{1}{\vartheta}} c_{B, i}^{\frac{\vartheta-1}{\vartheta}}\right]^{\frac{\vartheta}{\vartheta-1}}
$$

where $\vartheta$ represents the elasticity of substitution between the two types of consumption good and $a \in(0,1)$ is the utility weight of good of type $A$.

$R O W$ is represented by a large, risk-neutral agent, enjoying consumption of both goods. $R O W$ is relatively more patient than households in the economic union. Its stochastic discount factor, $\beta^{R O W}>\beta$ pins down the price of a risk-free asset in the world economy, $q^{R O W}=\beta^{R O W}$ The relative price of good $B$ in $R O W$ is given by $p_{B}^{R O W}$.

Risky sovereign debt. All countries in $I$ can buy risk-free assets issued by $R O W$. In addition, countries in the economic union issue risky debt on international financial markets. External debt is subject to a simple non-repayment friction: For a given amount of debt issued by $i$, lenders will fail to receive debt repayments with probability $1-\pi$. The exogenous repayment probability $\pi$ is function of current-period output $y_{i}$ and of the amount of debt issued. The function determining $\pi$ is increasing in $y_{i}$ and decreasing in issued debt 41 I denote by $b_{i}$ holdings by $i$ of risk-free assets issued by $R O W$. Negative values of $b_{i}$ indicate that $i$ owes debt. Adopting recursive notation, $b_{i}^{\prime}$ denotes currentperiod purchases of assets or, for $b_{i}^{\prime}<0$, debt issuance. As assets issued by $R O W$ are risk-free, $\pi=1$ if $b^{\prime}>0$. All agents have full information on non-repayment probabilities. Lenders in $R O W$ behave competitively, and they are willing to buy debt issued by $i$ as long as the price of this asset compensates them for non-repayment risk. The price at which $i$ can issue debt to $R O W$ is then given by the function

$$
q\left(y_{i}, b_{i}^{\prime}\right)=q^{R O W} \pi\left(y_{i}, b_{i}^{\prime}\right) .
$$

The debt price function inherits properties of $\pi$. In particular, the price of debt issued by $i$ is decreasing in its quantity. Borrowers always repay debt in full, even though a fraction of debt repayments are not received by lenders 42 This assumption captures in a simple way sovereign risk faced by creditors on international financial markets. In addition, as the probability of non-repayment is priced by lenders, borrowers have to take into account how the quantity of debt they issue affects its price. These features will be crucial to our analysis on the direction of international capital flows and intermediation in an economic union 43

\footnotetext{
${ }^{40} \mathrm{As}$ in other models of external debt this assumption ensures that $\beta / q^{R O W}<1$, ruling out divergence of external positions in presence of a borrowing limit. Schmitt-Grohe and Uribe (2003) review properties of alternative stationarity-inducing methods in similar frameworks.

${ }^{41}$ In addition, I assume that the function is continuously differentiable in both arguments.

${ }^{42} \mathrm{I}$ assume that resources paid by borrowers but not received by lenders are lost.

${ }^{43}$ The simplifying assumption that debt is always repaid in full allows me to study the pattern of intermediation and current account imbalances while ignoring optimal default choice by borrowers. In particular, I disregard strategic considerations by borrowers that would arise when issuing defaultable
} 
Equilibrium in no-bailout economy. Consider the case where, in all countries in the economic union $I$, no distortions are imposed on households' trade in financial assets. In particular, no bailout is offered in the event of losses suffered on risky assets. In this scenario, it is optimal for all countries in $i$ to trade in financial assets solely with $R O W 4$ The budget constraint of the representative household in $i$ is given in each period by:

$$
p c_{i}+q\left(y_{i}, b_{i}^{\prime}\right) b_{i}^{\prime}=p_{i} y_{i}+b_{i} .
$$

The relative price of the endowment good received by $i$ is given by $p_{i}$. This price takes value of unity if $i \in F$ and it receives an endowment of good $A$, and it is given by $p_{B}$ otherwise. The relative price of the consumption basket $c$ is given by $p=\left[a+(1-a) p_{B}^{1-\vartheta}\right]^{\frac{1}{1-\vartheta}}$. Again, bond holdings by $i$ are given by $b_{i}$. Negative values of this variable indicate that the economy owes debt to $R O W$. Note that the amount of resources that $i$ can raise on international financial markets is bounded, as the price at which debt is sold is decreasing in the amount issued.

The problem solved by the representative household in $i$ is to maximize expected lifetime utility (18) subject to the sequence of budget constraints (21):

$$
\begin{gathered}
V_{i}\left(y_{i}, b_{i}\right)=\max _{b_{i}^{\prime}, c_{i}}\left\{u\left(c_{i}\right)+\beta \mathbb{E}\left[V_{k}\left(y_{i}^{\prime}, b_{i}^{\prime}\right)\right]\right\} \\
\text { s.t. } p c_{i}+q\left(y_{i}, b_{i}^{\prime}\right) b_{i}^{\prime}=p_{i} y_{i}+b_{i},
\end{gathered}
$$

where $V_{i}$ denotes the value function of a generic country $i$, and it is given by either $V_{H}$ or $V_{F}$, depending on the type of good $i$ is endowed with. The solution can be summarized by the following intertemporal optimality condition,

$$
\frac{u^{\prime}\left(c_{i}\right)}{p}\left(q\left(y_{i}, b_{i}^{\prime}\right)+\frac{\partial q}{\partial b_{i}^{\prime}} b_{i}^{\prime}\right)=\beta \mathbb{E}\left[\frac{u^{\prime}\left(c_{i}^{\prime}\right)}{p^{\prime}}\right]
$$

equating the discounted marginal cost of an additional unit of debt with its marginal benefit, taking into account how a marginal increase in debt issued affects its price $q\left(y_{i}, b_{i}^{\prime}\right) .45$

Households allocate consumption across the two goods according to standard CES demand:

$$
c_{A, i}=a\left(\frac{1}{p}\right)^{-\vartheta} c_{i}, c_{B, i}=(1-a)\left(\frac{p_{B}}{p}\right)^{-\vartheta} c_{i} .
$$

Finally, the aggregate amount of good $B$ that countries in $I$ are endowed with is given by

$$
y_{B}=\int_{i \in H} y_{i} d i .
$$

debt whose price does not reflect the true default probability. While interesting, these issues fall beyond the scope of this paper. The reader is referred to Conesa and Kehoe (2015) for an analysis of the strategic interaction between sovereign borrowers and lenders in a model of self-fulfilling debt crisis.

${ }^{44}$ Risky assets issued by other economies in $I$ could be purchased by countries in the economic union. As these assets are priced by a risk-neutral agent, $R O W$, and they do not offer insurance against own income risk, it is not optimal for the risk-averse households in $I$ to hold positive amounts of them.

${ }^{45}$ Differently than in standard Euler equations in Eaton-Gersovitz frameworks, repayment occurs here in all states of the world. Hence, the expectation operator is conditional on information available in the current period only and not on a particular realization of the following-period exogenous state. 
Absent aggregate uncertainty, the aggregate endowment of goods in $I$ is constant by the law of large numbers, $\int_{i \in I} y_{i} d i=\mathbb{E}\left[y_{i}\right]$, where $\mathbb{E}\left[y_{i}\right]$ is the unconditional expected value of $y_{i}$. Given intra-temporal demand, (24), and defining aggregate consumption as $c=\int_{i \in I} c_{i} d i$, aggregate consumption of good $B$ in $I$ is given by:

$$
c_{B}=\int_{i \in I} c_{B, i} d i=(1-a)\left(\frac{p_{B}}{p}\right)^{-\vartheta} c .
$$

Due to the presence of transport costs, the relative price of $B$ prevailing in $I, p_{B}$, may differ from the one in $R O W, p_{B}^{R O W}$. If gains from trade are not sufficiently large to outweigh transport costs, no trade in good $B$ occurs between $I$ and $R O W 46$ When no trade with $R O W$ occurs, the aggregate endowment in $I$ of good $B$ is entirely consumed within the union, and $p_{B}$ is determined according to (25), with $c_{B}=y_{B}$.

I now define a competitive equilibrium in the world economy when no bailout is promised.

Definition 2. A recursive competitive equilibrium in the no-bailout economy is defined as a set of functions $p_{B}, c_{i}, c_{A, i}, c_{B, i}, b_{i}^{\prime}$ for $i \in\{H, F\}$ that solve households' optimization problems and clear the market for good $B$, as well as by a transition function $\Gamma$ for the joint distribution of $(y, b)$ :

- Consumption $c_{i}(y, b)$ and bond holdings $b_{i}^{\prime}(y, b)$ solve households' maximization problem (22) for countries $i$ in either $H$ or $F$

- Consumption of individual goods $c_{A, i}(y, b), c_{B, i}(y, b)$ solves the intra-temporal allocation (24)

- The relative price $p_{B}$ ensures market clearing for good $B, y_{B}=\int_{i \in I}(1-a)\left(\frac{p_{B}}{p}\right)^{-\vartheta} c_{i} d i$ if no trade in good $B$ between $I$ and $R O W$ occurs, $y_{B}=c_{B}$, and it is determined consistently with transport costs and with the price prevailing in world markets otherwise:

$$
p_{B}= \begin{cases}(1-\tau) p_{B}^{*} & \text { if } y_{B}>c_{B} \\ \frac{1}{(1-\tau)} p_{B}^{*} & \text { if } y_{B}<c_{B}\end{cases}
$$

- The Markov transition probability of the exogenous shock process for $y$ and the optimal choice of bond holdings determine the transition function $\Gamma$ for the joint distribution of $(y, b)$ in $H$ and $F$.

\footnotetext{
${ }^{46}$ Formally, no trade occurs in the range $p_{B} \in\left((1-\tau) p_{B}^{R O W}, \frac{1}{1-\tau} p_{B}^{R O W}\right)$. Trade in good $B$ between $I$ and $R O W$ only emerges if total demand for good $B$, (25), would imply $p_{B} \notin\left((1-\tau) p_{B}^{R O W}, \frac{1}{1-\tau} p_{B}^{R O W}\right)$ when $c_{B}=y_{B}$.
} 
Equilibrium in the economy with full bailout promises. Consider now the case where, in all countries in $I$, the domestic government offers a bailout promise to all households holding risky assets issued by other members of the union. The government in each $i$ offers to its residents a full bailout promise, if they were not to receive payments they are owed on holdings of risky sovereign debt. Due to the full bailout promise, households perceive assets issued by all other union members as being perfect substitutes for each other, even though they differ in terms of repayment probabilities. The bailout promise is only offered if the total amount of liabilities issued by each individual borrower $j$ falls below a certain threshold $\bar{b}: b_{j} \geq \bar{b}\left(y_{j}\right)$ 낵 In every period, the government in each $i$ finances bailout payments to asset holders in $i$ by setting a lump-sum tax $T_{i}$ that is paid by all households in the country. Define $\tilde{b}_{i, j}$ as holdings by the representative household in $i$ of debt issued by $j$. The amount of resources that is lost by the representative household in $i$ on risky assets issued by other union members is given by $\int_{j \in I}\left[1-\pi\left(y_{j,-1}, \tilde{b}_{j}\right)\right] \tilde{b}_{i j} d j$. As the government fully compensates asset holders for losses incurred on risky debt, the amount of tax that is paid by the representative household in each period is exactly equal to the aggregate amount of resources that are lost by bond holders 48

$$
T_{i}=\int_{j \in I}\left[1-\pi\left(y_{j,-1}, \tilde{b}_{j}\right)\right] \tilde{b}_{i j} d j .
$$

Countries in the union only differ ex-ante in terms of the type of good they are endowed with, which is given by $A$ or $B$ depending on whether $i$ belongs to the set $F$ or $H$. Depending on their wealth and realization of the exogenous shock, economies optimally choose to behave as gross savers, buying gross assets issued by union members and issuing gross liabilities to $R O W$, or whether to be borrowers instead, simply issuing debt to other countries in the union.

In gross saving countries, households can buy assets issued by other countries in the union and they can issue liabilities to $R O W$. I define $\tilde{b}_{i}=\int_{j \in I} \tilde{b}_{i j} d j$. as the aggregate amount of union-issued assets that is held by the representative household in country $i$. The price bid by union members for bonds issued by other countries in $I$ is given by $\tilde{q}$. Due to perfect substitutability implied by the full bailout promise, the price $\tilde{q}$ is identical across all issuers in $I$. As in the no-bailout setting, $b_{i}$ denotes holdings by $i$ of risk-free bonds issued by $R O W$. This variable takes negative values when $i$ owes gross liabilities to $R O W$. Beginning-of-period net wealth of the representative household in a gross saving country is defined as gross assets, net of gross liabilities owed to $R O W$ and of taxes paid to the domestic government: $n_{i}=\tilde{b}_{i}+b_{i}-T_{i}$. Note that, even though it enjoys a full bailout promise, the representative household still incurs in losses on holdings of gross assets, as bailout transfers are financed by taxation. The budget constraint of the

\footnotetext{
${ }^{47} \mathrm{As}$ in Section 3, this restriction on bailout promises is required to impose a borrowing limit and to prevent borrowers' liability positions from growing unbounded. In an endogenous sovereign default setting, a similar assumption is made by Ayres, Navarro, Nicolini and Teles (2015).

${ }^{48} \mathrm{By}$ the law of large numbers, $\pi\left(y_{j}, b_{j}^{\prime}\right)$ both indicates the probability of repayment by a given economy with $y=y_{j}, b^{\prime}=b_{j}^{\prime}$ as well as the total fraction of resources that are received by a lender on his holdings of assets issued by all economies with $y=y_{j}, b^{\prime}=b_{j}^{\prime}$.
} 
representative household in a gross saving country is given by:

$$
p c_{i}+\tilde{q} \tilde{b}_{i}^{\prime}+q\left(y_{i}, b_{i}^{\prime}\right) b_{i}^{\prime}=p_{i} y_{i}+n_{i}
$$

describing how purchases of consumption and gross assets are financed with own resources, $n_{i}$, and by issuing liabilities to $R O W$.

The problem faced by the representative household in each country $i$ includes as a state variable aggregate wealth in the country itself, $N_{i}$. Aggregate wealth is a state variable as it allows individual households to forecast the next-period value of gross asset holdings in $i$, which determines in turn next-period taxation, according to (27) 49 I define $\Phi\left(y_{i}, N_{i}\right)$ as the forecast for the next-period value of aggregate wealth, $N_{i}^{\prime}$, given the current aggregate state in $i,\left(y_{i}, N_{i}\right)$. The other state variables for the household are given by its net wealth, $n_{i}$, and by the realization of the endowment shock $y_{i}$. The maximization problem solved by the representative household in a gross saving country is the following:

$$
\begin{aligned}
V_{i}^{S}\left(y_{i}, n_{i}, N_{i}\right) & =\max _{b_{i}^{\prime}, \tilde{b}_{i}^{\prime}>0,}\left\{u\left(c_{i}\right)+\beta \mathbb{E}\left[V_{i}\left(y_{i}^{\prime}, n_{i}^{\prime}, N_{i}^{\prime}\right)\right]\right\} \\
\text { s.t. } & p c_{i}+q\left(y_{i}, b_{i}^{\prime}\right) b_{i}^{\prime}+\tilde{q} \tilde{b}_{i}^{\prime}=p_{i} y_{i}+n_{i} \\
& n_{i}^{\prime}=\tilde{b}_{i}^{\prime}+b_{i}^{\prime}-T_{i}^{\prime} \\
& N_{i}^{\prime}=\Phi\left(y_{i}, N_{i}\right)
\end{aligned}
$$

Country $i$ is not restricted to be a gross saver in the following period, hence the continuation value of households is not given by $V_{i}^{S}(\cdot)$ but rather by $V_{i}(\cdot)$, to be defined shortly. I define $\varpi$ as the subset of the state space where a solution to the problem in (29) exists with positive holdings of gross assets, $\tilde{b}_{i}^{\prime}>0$ : $\varpi=\left\{(y, n, N) \mid \tilde{b}_{i}^{\prime}(y, n, N)>0\right\}$. The solution to the household problem implies a law of motion for net wealth of the representative household, $n^{\prime}\left(y_{i}, n_{i}, N_{i}\right)$, which, in general, differs from the perceived aggregate one, $N_{i}^{\prime}=\Phi\left(y_{i}, N_{i}\right)$. The two must coincide in equilibrium.

The problem can be summarized by the following system of two Euler equations, for gross liabilities and gross assets, respectively:

$$
\begin{aligned}
u^{\prime}\left(c_{i}\right)\left(q\left(y_{i}, b_{i}^{\prime}\right)+\frac{\partial q}{\partial b_{i}^{\prime}} b_{i}^{\prime}\right) & =\beta \mathbb{E}\left[u^{\prime}\left(c_{i}^{\prime}\right)\right] \\
u^{\prime}\left(c_{i}\right) \tilde{q} & =\beta \mathbb{E}\left[u^{\prime}\left(c_{i}^{\prime}\right)\right] .
\end{aligned}
$$

In a gross saver country, the portfolio of gross asset and liability positions of the representative household is set by equating the price of gross assets $\tilde{q}$ with the amount of resources obtained by issuing a marginal unit of debt, $q\left(y_{i}, b_{i}^{\prime}\right)+\frac{\partial q}{\partial b_{i}^{\prime}} b_{i}^{\prime}$, as gross assets

\footnotetext{
${ }^{49}$ The optimization problem in Bianchi (2011) exhibits similar features, in the presence of a pecuniary externality. Here, the household fails to internalize the effect on taxation of its choice for gross assets. There, household choices determine relative goods prices that affect in turn the severity of a borrowing constraint.
} 
and gross liabilities are equally perceived as risk-free. In equilibrium, the amount of debt issued to $R O W$ is pinned down by the arbitrage condition:

$$
\tilde{q}=q\left(y_{i}, b_{i}^{\prime}\right)+\frac{\partial q}{\partial b_{i}^{\prime}} b_{i}^{\prime}
$$

In borrowing countries, the representative household issues debt to other union members at the constant price $\tilde{q}$. Country $i$ is a borrower if, given the vector of state variables of the representative household $\left(y_{i}, N_{i}, n_{i}\right)$, there exists no solution to the maximization problem in (29) with positive holdings of gross assets, $\tilde{b}_{i}^{\prime}>0.50$ The budget constraint of the representative household in a borrowing country is given by:

$$
p c_{i}+\tilde{q} \tilde{b}_{i}^{\prime}=p_{i} y_{i}+n_{i}
$$

The problem faced by the representative household in a borrowing country is the following:

$$
\begin{aligned}
V_{i}^{B}\left(y_{i}, n_{i}, N_{i}\right) & =\max _{\tilde{b}_{i}^{\prime} \geq 0}\left\{u(c)+\beta \mathbb{E}\left[V_{i}\left(y_{i}^{\prime}, \tilde{b}_{i}^{\prime}, N_{i}^{\prime}\right)\right]\right\} \\
\text { s.t. } & p c_{i}+\tilde{q} \tilde{b}_{i}^{\prime}=p_{i} y_{i}+n_{i} \\
& \tilde{b}_{i}^{\prime} \geq \bar{b}\left(y_{i}\right) \\
& n_{i}^{\prime}=\tilde{b}_{i}^{\prime} \\
& N_{i}^{\prime}=\Phi\left(y_{i}, N_{i}\right) .
\end{aligned}
$$

Households in borrowing countries do not purchase gross assets, hence no taxes are due in the following period, as there are no bailout transfers to be made to residents by the domestic government. Next-period net wealth simply follows from the amount of debt issued in the current period, as borrowers always repay their debt in full. The borrowing constraint $\tilde{b}_{i}^{\prime} \geq \bar{b}\left(y_{i}\right)$ stems from the limited bailout promise that is offered to gross savers in the union, as they are only willing to bid $\tilde{q}$ on debt issued by $i$ if the amount issued is below $\bar{b}\left(y_{i}\right)$. The Euler equation describing the solution to borrowers' problem is the following:

$$
u^{\prime}\left(c_{i}\right) \tilde{q}=\beta \mathbb{E}\left[u^{\prime}\left(c_{i}^{\prime}\right)\right] .
$$

Borrowers do not take into account how marginal debt issues affect the repayment probability $\pi$. This occurs due to the presence of the bailout promise, as lenders do not require to be compensated for non-repayment risk associated with individual assets.

For gross savers and borrowers alike, the intra-temporal allocation of consumption across the two goods, $A$ and $B$, is determined according to CES demand, (24), as in the no-bailout setting.

\footnotetext{
${ }^{50}$ In principle, it should be possible for borrowing countries to be able to issue debt to $R O W$. This restriction can be relaxed only at substantial cost, from a computational point of view. In the numerical solution of this model, only a small subset of borrowing countries would issue debt at a higher price if trading with $R O W$.
} 
I can now define the value function of the representative household in a generic country $i, V_{i}\left(y_{i}, n_{i}, N_{i}\right)$, as the value function of a gross saving country, $V_{k}^{S}\left(y_{i}, n_{i}, N_{i}\right)$, in the subset of the state space $\varpi$ where a solution to the problem in (29) with positive $\tilde{b}^{\prime}$ exists. In the complementary subset of the state space, the country $i$ is a borrower and its value function is given by $V_{i}^{B}\left(y_{i}, n_{i}, N_{i}\right)$ :

$$
V_{i}\left(y_{i}, N_{i}, N_{i}\right)= \begin{cases}V_{i}^{S}\left(y_{i}, N_{i}, N_{i}\right) & \text { if }(y, N) \in \varpi \\ V_{i}^{B}\left(y_{i}, N_{i}, N_{i}\right) & \text { otherwise. }\end{cases}
$$

I now define an equilibrium in the economy with bailout promises.

Definition 3. A recursive competitive equilibrium in the economy with bailout promises is defined as a set of functions $c_{i}, c_{A, i}, c_{B, i}, \tilde{b}_{i}^{\prime}, b_{i}^{\prime}, \theta_{i}$ for $i \in\{H, F\}, p_{B}, \tilde{q}$ that solve households' optimization problems and clear the markets for assets traded in the union and for good $B$, as well as by a perceived law of motion for wealth $\Phi\left(y_{i}, N_{i}\right)$ and a transition function $\Gamma$ for the joint distribution of $(y, N)$ :

- In the state space subset $\varpi$ where a solution to the problem in (29) with positive $\tilde{b}$ exists, consumption $c_{i}(y, n, N)$, bond holdings of union-issued assets $\tilde{b}_{i}^{\prime}(y, n, N)$ and of ROW assets $b_{i}^{\prime}(y, n, N)$ solve gross savers' maximization problem (29) for countries $i$ in either $H$ or $F$

- In the complement subset to $\varpi$, consumption $c_{i}(y, n, N)$ and bond holdings of unionissued assets $\tilde{b}_{i}^{\prime}(y, n, N)$ solve borrowers' maximization problem (33) for countries $i$ in either $H$ or $F$

- In gross saving countries, taxes $T_{i}$ are consistent with losses incurred on gross assets held in each country, according to (27).

- Consumption of individual goods $c_{A, i}(y, b), c_{B, i}(y, b)$ solve intra-temporal allocation (24) for all $i$

- The price $\tilde{q}$ ensures market clearing for assets traded within the union:

$$
\int \tilde{b}_{i} d i=0
$$

- The relative price $p_{B}$ ensures market clearing for good $B, y_{B}=(1-a)\left(\frac{p_{B}}{p}\right)^{-\vartheta} \int_{i \in I} c_{i} d i$ if no trade in good $B$ between $I$ and $R O W$ occurs, $y_{B}=c_{B}$, and it is determined consistently with transport costs and with the price prevailing in world markets otherwise:

$$
p_{B}= \begin{cases}(1-\tau) p_{B}^{*} & \text { if } y_{B}>c_{B} \\ \frac{1}{(1-\tau)} p_{B}^{*} & \text { if } y_{B}<c_{B}\end{cases}
$$


- The aggregate law of motion for wealth perceived by the representative household in each country, $N^{\prime}=\Phi(y, N)$, coincides with the one implied by the optimization problems (29) and (33).

- The Markov transition probability for the exogenous shock and the optimal choice of bond holdings determine the the transition function $\Gamma$ for the joint distribution of $(y, N)$ in $H$ and $F$.

Calibration. The model cannot be solved analytically and I obtain its numerical solution via a global solution method. The algorithm is described in detail in Appendix A.6. Choices for parameter values closely follow the literature on open-economy macroeconomics. Parameter values and calibration targets are reported in Table 1. In order to compare simulated series from the model with empirical evidence on the current account, the model is calibrated at quarterly frequency.

The subjective discount factor in $R O W, q^{R O W}$, is set to match a world risk-free real interest rate of $2.5 \%$, consistently with evidence reported in King and Low (2014) for the world real interest rate. Due to the presence of a downward secular trend in world interest rates, this value understates the risk-free rate prevailing in the pre-EMU period, while it can describe well the low interest rate environment observed in the world economy in the 2000s 51

The exogenous function $\pi\left(y, b^{\prime}\right)$, determining the probability that sovereign debt repayments are not received by lenders, takes value of unity for $b^{\prime} \geq 0$ and it has the following functional form otherwise:

$$
\pi\left(y, b^{\prime}\right)=\frac{(\eta-1) \bar{b}^{\eta}}{(\eta-1) \bar{b}^{\eta}+\left(-b^{\prime} / y\right)^{\eta}}
$$

where $\bar{b}$ and $\eta$ are parameters. The price of debt issued to $R O W$ by economies in $I$ is then given by $q\left(y, b^{\prime}\right)=q^{R O W} \pi\left(y, b^{\prime}\right)$ which is continuous, differentiable and positive for all real values of $b^{\prime}$. The upper bound for resources raised on international financial markets when debt is priced by $R O W$ is given by the solution to

$$
\max _{b^{\prime}}\left(-q\left(y, b^{\prime}\right) b^{\prime}\right) \text {. }
$$

The value for $b^{\prime}$ that maximizes resources raised by borrowing is given by

$$
\underset{b^{\prime}}{\arg \max }\left(-q\left(y, b^{\prime}\right) b^{\prime}\right)
$$

which, from the function in (36), is given by $y \bar{b}$. I set the upper threshold for borrowers' debt above which bailout promises are not offered to this value: $\bar{b}(y)=y \bar{b}$.

\footnotetext{
${ }^{51}$ Empirical evidence on the secular decline in interest rates is, again, presented by King and Low (2014). Thwaites (2015) presents an explanation based on the contextual observation of a secular decline in the price of investment goods.
} 
The parameters $\bar{b}$, and $\eta$ are set to match properties of the distribution of external positions and interest rates in euro area economies before the inception of the monetary union. I set the parameter $\bar{b}$ to calibrate the aggregate net foreign asset-to-GDP ratio for countries in $I$. Lane and Milesi-Ferretti (2007) report a value of $-10.3 \%$ of this variable for the euro area in 1998. As data are not reported prior to this year, I set this variable to a slightly higher value, $-7.5 \%$, noting that the net foreign asset position of all major member economies was deteriorating in the years preceding 1998.

By governing the elasticity of non-repayment probability with respect to liabilities, the parameter $\eta$ can be set to target the dispersion in interest rates on debt issued by countries in $I$. The spread in the real interest rate paid by borrowers between the poorest and wealthiest decile of the stationary distribution in $I$ is set to 50 basis points. While this value seems low when compared to the pre-EMU spread in benchmark nominal interest rates on European countries' government bonds, large inflation differentials that were present between these economies at the time need to be taken into account. For instance, the spread between benchmark nominal interest rates on Italian and German government debt equalled 320 basis points in 1996. This difference fell to 60 basis points when accounting for the inflation differential between the two countries 52

In order to rule out divergence of net foreign asset positions of individual countries in $I$, the subjective discount factor in $I, \beta$ is set to be slightly lower that the one in $R O W$. By implication, the median real interest rate in $I$ is slightly higher than the world risk-free rate, by 25 basis points.

Endowment streams are determined according to the autoregressive stochastic process:

$$
\log \left(y_{i, t}\right)=\left(1-\rho_{y}\right) \mu_{y}+\rho_{y} \log \left(y_{i, t-1}\right)+\epsilon_{i, t},
$$

where $\epsilon_{i, t}$ is a normally distributed, zero-mean, i.i.d shock with standard deviation $\sigma_{\epsilon}$. To normalize the unconditional mean of $y_{i}$ to unity, $\mu_{y}$, is set to equal $-\frac{1}{2} \frac{\sigma_{\epsilon}^{2}}{1-\rho_{y}^{2}}$. The standard deviation $\sigma_{\epsilon}$ and the autoregressive parameter $\rho_{y}$ are set to match standard deviation and autocorrelation of $1.5 \%$ and 0.88 , respectively, of HP-filtered GDP for euroarea economies. In the numerical solution, the process is approximated by a discretized process obtained via the Rouwenhorst method (Rouwenhorst, 1995, Kopecky and Suen, 2010).

Relative risk aversion of households in $I, \gamma$, is set to the standard value of 253 The elasticity of intra-temporal substitution between $A$ and $B$ good, $\vartheta$, is set to 0.85 , following the value adopted in Corsetti, Dedola, Leduc (2008) for the elasticity between domestic and foreign goods. The relative mass of countries in the set $H$, specialized in output of high-trade cost good $B$ is given by $1-\kappa$, which I set to 0.15 to match the relative size of Greece, Portugal and Spain to the euro area, consistently with evidence of low average tradability of output in these countries, as presented in Section 2 . The utility weight $a$ is set to equal relative abundance of the two goods, $\kappa$, in order to normalize to unity the relative price $p_{B}$, in autarky. Finally, the iceberg transport $\operatorname{cost} \tau$ is set to the value

\footnotetext{
${ }^{52}$ Source: Eurostat, EMU convergence criterion bond yields and OECD, consumer price index.

${ }^{53}$ See, e.g. Backus, Kehoe, Kydland (1994), Corsetti, Dedola, Leduc (2008).
} 
Table 1: Parameter values

\begin{tabular}{llll}
\hline \hline Calibrated Parameter & & Value & Target / Source \\
\hline \hline Discount factor in $I$ & $\beta$ & .9914 & Average interest rate in $I$ \\
Discount factor in $R O W$ & $\beta^{R O W}$ & .9938 & World real interest rate \\
Relative risk aversion in $I$ & $\gamma$ & 2 & Standard \\
Bailout promise limit & $\bar{b}$ & 1.5 & Average euro area NFA \\
Repayment probability, debt elasticity & $\eta$ & 4 & Italy - Germany spread, pre-EMU \\
Relative size of $H, F$ & $\kappa$ & .85 & Relative size of Greece, Portugal, Spain \\
Utility weight of good $A$ & $a$ & $=\kappa$ & Normalize $p_{B}=1$ in autarky \\
Intra-temporal elasticity of substitution & $\vartheta$ & .85 & Corsetti, Dedola, Leduc (2008) \\
Output process, autocorrelation & $\rho_{y}$ & .88 & Euro area GDP \\
Output process, standard deviation & $\sigma_{\epsilon}$ & .015 & Euro area GDP \\
\hline \hline
\end{tabular}

of $3 \%$. This value is extremely low in comparison with estimates for typical trade costs presented by Anderson and Van Wincoop (2004). Even for this value of $\tau$, no trade in $B$ with $R O W$ emerges in the numerical solution of this model 54

\subsection{Imbalances, intermediation and crisis}

The objective of the model introduced in this section is to perform a quantitative analysis of the recent euro area experience, in terms of current account imbalances, expansion of gross financial positions and crisis. In particular, this model aims to evaluate the role of subsidies on cross-border holdings of assets in contributing to these facts. To this purpose, I present here the main properties of the steady state equilibrium allocation in the two model economies I introduce, the one with no bailout and the one with a full bailout promise. I then conduct two main quantitative experiments, both describing the dynamic transition of the model economy after a shock. The shocks I consider allow me to analyze the introduction of a subsidy on cross-border asset holdings and the occurrence of a debt crisis in the economic union.

First, I define the steady state equilibrium allocation in the two economies of this model. Properties of the equilibrium differ substantially between the economies with and without bailout promise. I describe a key element of the steady state allocation, namely the policy function for the current account balance in individual countries. Properties of this policy function are crucial to determine the equilibrium distribution of wealth in the economic union $I$. I then proceed to analyze differences in the distribution of wealth that emerge in the two model economies considered, focusing in particular on differences in terms of dispersion of net foreign asset positions. I then compare features

\footnotetext{
${ }^{54}$ Relative demand and supply for the two goods are set to be equal in autarky. Trade in $B$ with $R O W$ would only emerge in the presence of extremely large changes in demand by countries in $I$, which are not considered here. Large shocks to supply are ruled out by stationariety of the process for $y_{i}$ and by the law of large numbers.
} 
of the equilibrium distribution with empirical evidence for the euro area.

Second, I present results from the first of two quantitative experiments. I analyze the initial phase of the EMU, characterized by current account imbalances and intermediation of gross capital flows, as discussed in Section 2. In order to do so, I consider the effects of a shock consisting in the introduction of a subsidy on cross-border holdings of assets, represented by the full bailout promise. I perturb with this shock the steady state equilibrium of the model economy with no bailout promises, which is calibrated to replicate quantitative features of euro area countries prior to the introduction of the single currency. No additional shocks hit the model economy, which is left to transition towards its new steady state. To analyze current account imbalances, I describe in this context the simulated path of net foreign assets of individual countries in $I$, focusing in particular on choices by countries at the opposite ends of the wealth distribution. In addition, I compare model predictions in terms of gross external positions with the experience of the euro area core. To do so, I present the path of gross asset and liability positions of savers in the model, which describes a pattern of intermediation of international capital flows.

Finally, I conduct an additional experiment to study the later phase of the EMU, characterized by the occurrence of a sovereign debt crisis. In particular, the aim of this experiment is to investigate the role in a crisis of linkages that are distinctive of an economic union. In the steady state equilibrium of the economy with bailout promise, countries are linked by cross-border financial exposures, as well as by trade integration. To simulate a debt crisis, I perturb this equilibrium allocation with a shock amounting to a fall in the value of union-issued assets held by gross savers. This shock allows me to concentrate on general equilibrium effects of a debt crisis in an economic union, arising due to a deterioration in lenders' net wealth 55 I analyze in this context the heterogeneous effects of the crisis on countries in $I$ that differ in terms of wealth and exposure to trade with union partners, highlighting the interaction in a crisis between financial and trade linkages among countries in a union.

Steady states. A steady state is defined as an equilibrium allocation where all aggregate variables in $I$ are constant, namely the wealth distribution, the relative price $p_{B}$ and, in the economy with bailout promise, the price of union-issued assets $\tilde{q}$. Note that, even in a steady state allocation, variables characterizing individual countries are not necessarily constant. While aggregate uncertainty is not present, idiosyncratic endowment shocks induce individual countries to accumulate and run down assets. As their external assets fluctuate, countries move within the equilibrium wealth distribution, which is constant in steady state.

The policy function for current account balances of individual countries in $I$ determines the evolution of their net foreign asset position. Differences in this policy function between the no-bailout and bailout economy stem from the key element characterizing

\footnotetext{
${ }^{55}$ A similar analysis is conducted by Arellano and Bai (2014), who focus on renegotiation after default. Direct output costs of default in crisis countries are ignored here, as I focus on feedback and amplification effects that are distinctive of an economic union. These have been treated extensively in the literature, see e.g. Mendoza and Yue (2012).
} 


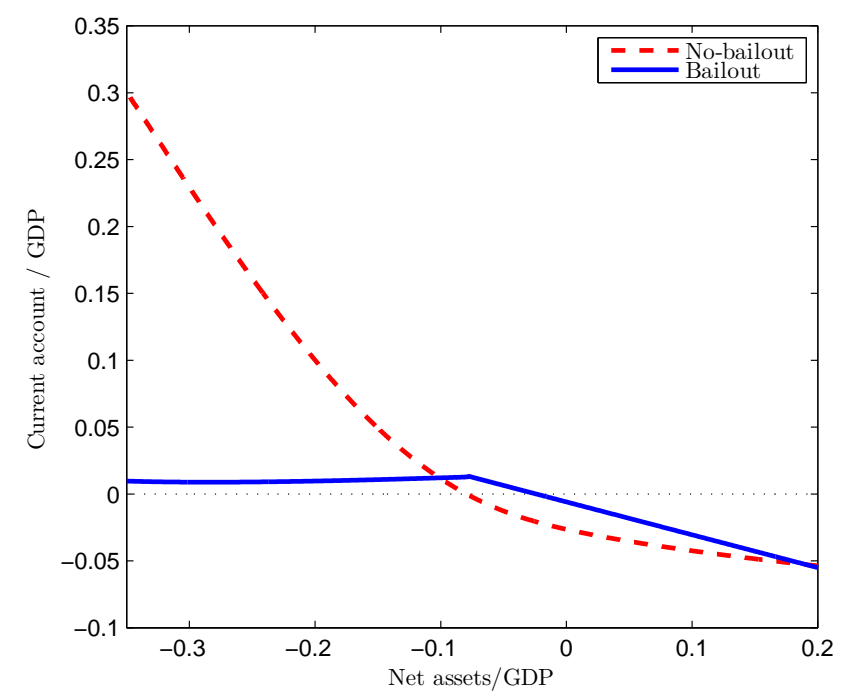

Figure 5: Steady state policy functions for current account, $N^{\prime}-N$, as function of net wealth, for a country in $F$ with realization of the endowment process equal to its stationary mean. No-bailout (red, dashed line) and bailout (blue, solid line) allocations.

the allocations, namely the determination of borrowing costs. In the no-bailout allocation, the price of debt is decreasing in the amount issued, via the function $q\left(y, b^{\prime}\right)$. This is not the case in the bailout allocation, where individual borrowers can issue debt at the constant price $\tilde{q}$. Figure 5 presents the current account balance policy function in the two model economies, for a country in $F$ with realization of the endowment process equal to its stationary mean and for a range of values of net foreign assets 56

Two key differences emerge between the policy functions arising in equilibrium in the two model economies. First, a country with high debt chooses to optimally run a large current account surplus in the no-bailout economy, while this is not the case in the economy with bailout promises. This result is intuitive when we consider the difference in borrowing costs faced by debtors in the two models. Through the function $q\left(y, b^{\prime}\right)$, a highly indebted borrower pays a high interest rate in the no-bailout allocation, and it is induced to rapidly reduce its external liability position. Consider the case of a country with net liabilities equal to $35 \%$ of yearly output. In the no-bailout economy, this country would run an extremely large current account surplus, equal to $30 \%$ of quarterly output 57 In the economy with bailout promise, the current account surplus of a country with the

\footnotetext{
${ }^{56}$ In steady state, the policy function for a similar country in $H$ would be practically identical and it is not shown here. This is due to the fact that the steady state relative price $p_{B}$ is constant and close to unity.

${ }^{57}$ I express stock variables as ratios of yearly output, as is commonly done when discussing external debt ratios. As the model is calibrated at quarterly frequency, however, I express flow variables such as current account balances as ratios to quarterly output. Mean yearly output is simply given by mean quarterly output times four, so that debt equal to $35 \%$ of yearly output corresponds to $140 \%$ of quarterly output.
} 


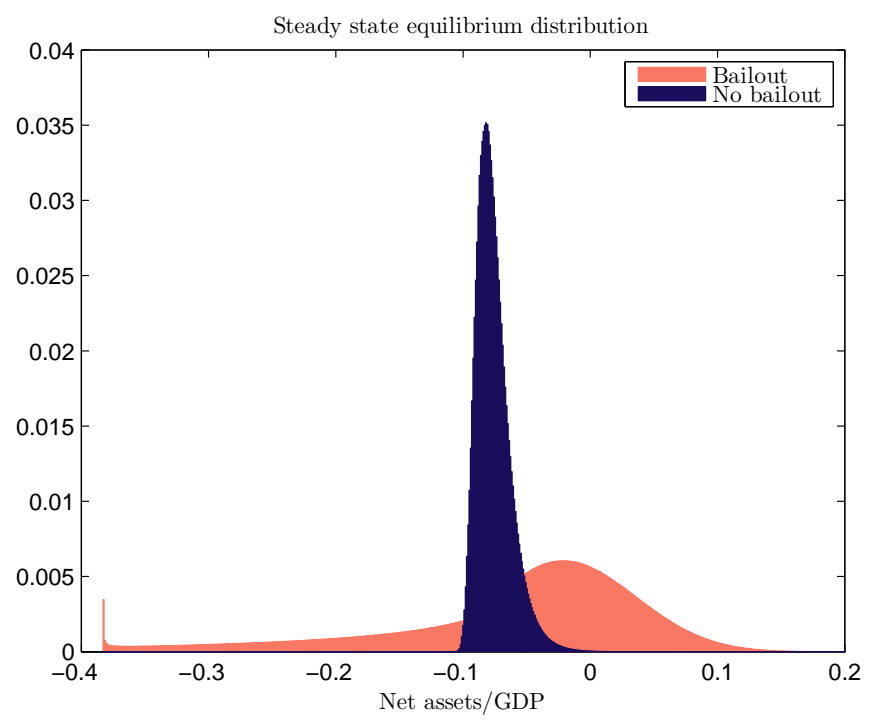

Figure 6: Steady state wealth distributions. No-bailout and bailout equilibrium allocations. Values on the $y$-axis represent masses of countries in intervals of the wealth distribution spanning $0.1 \%$ of mean yearly output.

same level of debt would only equal $1.2 \%$ of quarterly output, as the constant price of debt $\tilde{q}$ induces more moderate savings.

Second, countries with low debt or positive net wealth are induced to save more in the economy with bailout promises. A country with net external liabilities equal to $8 \%$ of yearly output would run a balanced current account position in the no-bailout economy, while it would run a current account surplus in the economy with bailout promises, corresponding to $1.2 \%$ of quarterly output. In the bailout economy, current account surpluses by wealthy countries arise due to two channels. First, the bailout promise induces households to perceive union-issued assets as risk-free. The price of these assets is given by $\tilde{q}$, which is lower than that of a truly risk-free asset, $q^{R O W}$. The low price of assets perceived as risk-free constitutes an incentive to increase saving. Second, households in gross saving economies pay in each period a tax to their domestic government to finance bailout transfers on risky assets. The expectation of positive future taxes further induces saving, as households do not internalize the effect on taxation of their risky assets purchases.

Differences across the two model economies in terms of policy functions for current account balances are reflected in the distribution of net foreign assets arising in the two allocations. Figure [6 displays the steady state distribution of net foreign assets in the no-bailout economy and in the economy with full bailout promises.

The net foreign assets distribution is substantially wider in the economy with full bailout promises. The difference in net foreign assets between a country at the ninetieth percentile of the wealth distribution and one at the tenth percentile amounts to $25 \%$ of mean output in the steady state of the economy with full bailout promises. For comparison, the same difference amounts to just $3 \%$ of output in the economy with no 


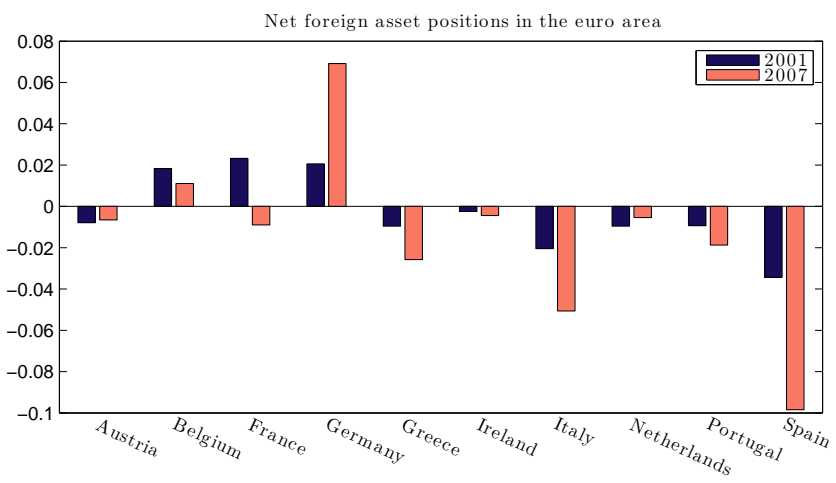

Figure 7: Net foreign asset positions of core and periphery euro area economies, 2001 and 2007, expressed as ratio of euro area GDP. Source: Lane and Milesi-Ferretti (2007) and own calculations.

bailout. As the stochastic process driving endowment realizations is the same in the two economies, the widening of the distribution is due to differences in agents' optimal choices across the two models.

The two main differences across policy functions in the two model economies are crucial to explain differences in the equilibrium distributions of net foreign assets. First, choices made by high-debt countries explain why we observe more mass to the left of the distribution in the economy with bailout promises. High saving by countries with high debt in the no-bailout economy implies that the mass of countries in this tail of the distribution falls steeply as net foreign assets decrease. In the economy with bailout promises, as high-debt countries run smaller current account surpluses, a larger mass of countries can be found in correspondence of high negative levels of net foreign assets. In addition, a positive mass of countries is against the borrowing constraint implied by $\bar{b}$. Second, in the economy with bailout promises, the stronger incentive to save implied by the high perceived return on union-issued assets leads wealthy countries to run smaller current account deficits. As economies with positive net foreign asset positions run down their wealth to a lesser degree when a bailout promise is offered, a larger mass of countries is found in the right tail of the wealth distribution.

The widening of net foreign assets distributions observed comparing steady state equilibria in the two model economies is comparable with the one observed in the euro area between the inception of the monetary union and the global financial crisis. Figure 7) shows net foreign asset positions of core and periphery countries in the euro area in two different years, in 2001, at the inception of the monetary union, and before the global financial crisis, in 2007, as ratio to euro area GDP 58 The range of net foreign asset positions in these countries widened substantially in this period, rising from $6 \%$ of euro area GDP in 2001 to $16 \%$ in 2007, similarly to the the prediction of this model on the effects of of subsidies on cross-border holdings of assets 59

\footnotetext{
${ }^{58}$ Data are drawn from Lane and Milesi-Ferretti (2007).

${ }^{59}$ The widening of euro area net foreign asset positions is not entirely surprising, given the observation of current account imbalances discussed in Section 2 and the close relationship between the two variables.
} 
The inception of the EMU: Current account imbalances and intermediation. I present here results for the first of the two quantitative experiments I conduct by means of the infinite-horizon model. Aim of this experiment is to quantitatively assess the implications on current account balances and gross capital flows of the introduction of a full bailout promise on assets issued within the union. First, I will describe the type of experiment considered and the shock hitting the model economy. Second, I will present simulations for equilibrium net foreign asset positions in two countries located at opposite tails of the wealth distribution. Finally, I will analyze the path of gross capital flows in a country with relatively high initial net foreign assets.

The experiment I conduct is the following. Consider the steady state equilibrium allocation of the economy with no bailout promises. As discussed, parameter values are calibrated for quantitative properties of this allocation to replicate features of euro area economies, before the inception of the monetary union. I perturb this equilibrium allocation by introducing a full bailout promise on assets issued within the union. The shock is entirely unexpected by agents in the model. Thereafter, no other shocks hit the economy, which corresponds now to the economy with full bailout promise described in Section 4.1.

I consider the dynamic transition of variables chosen in equilibrium by individual countries during the transition towards the new steady state of the economy. The effects of the shock considered are heterogeneous across countries in the distribution 60 In order to correctly isolate the effects of the shock on individual countries, I compare simulated series for choices made during the transition by a generic economy $i$, characterized by the pair $\left(y_{i}, N_{i}\right)$, with choices the same country would make in a counterfactual simulation where the bailout promise is not introduced 61

To replicate the experience of peripheral countries in the euro area, characterized by low relative GDP and negative net foreign asset positions at the inception of the monetary union, I present in Figure 8 the path of net foreign assets chosen during the transition by a country with low endowment realization and high debt. This country is characterized by a realization of $y_{i}$ two standard deviations below the stationary mean and net foreign assets corresponding to the tenth percentile of the wealth distribution.

Net foreign assets of the high debt country deteriorate substantially along the transition after the shock. In the first 24 quarters, net foreign liabilities approximately double, rising from $9 \%$ of yearly output to $17 \%$. The magnitude of this increase in debt is comparable with the one observed in the periphery of the euro area. Between 2001 and 2007 net foreign liabilities of peripheral countries increased by $160 \%$ as a ratio to euro area GDP, as shown already in Figure 7.

\footnotetext{
${ }^{60}$ This is due to the fact that policy functions characterizing agents' optimal choice are not, in general, linear in the state variables.

${ }^{61}$ In general, choices made in the counterfactual simulation will not be constant, as the country is hit by idiosyncratic shocks and it moves within the stationary distribution. Hence, I need to ensure that simulated series do not reflect implications of a particular draw of idiosyncratic shocks during the transition. I address this concern by presenting median values of variables, given a large number of simulations for the sequence of idiosyncratic shocks hitting $i$. The same draws for the exogenous process are considered across transition and counterfactual simulations.
} 


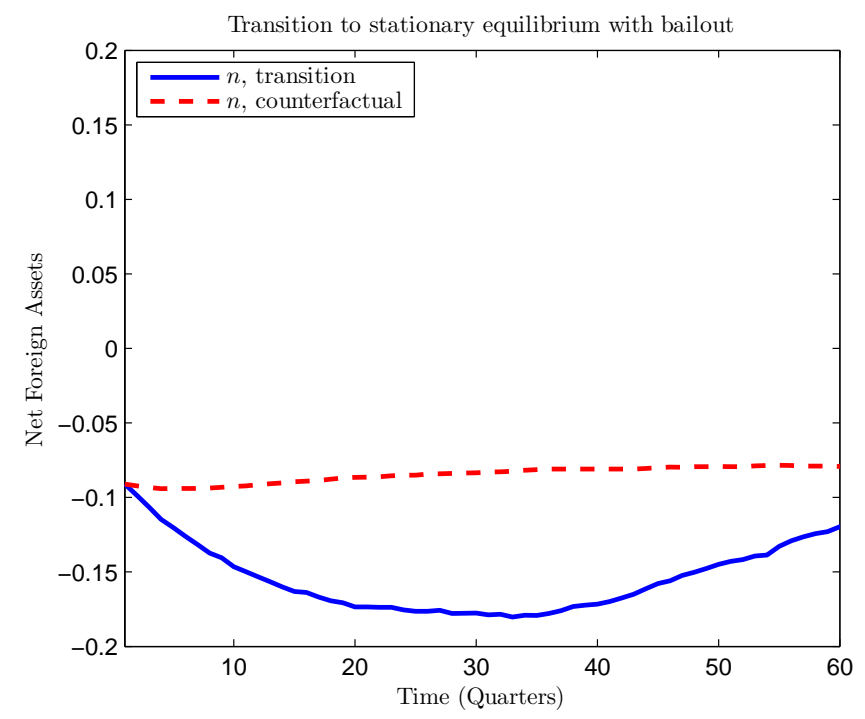

Figure 8: Transition after introduction of bailout promise. Net foreign asset position chosen by a highdebt, low-income country (blue, solid line). The red, dashed line displays the counterfactual simulation for the same country if no bailout promise is introduced.

The deterioration of the net foreign asset position is due to the introduction of the bailout promise, and to the ensuing reduction in borrowing costs. Consider the path of net foreign assets chosen in the counterfactual simulation, where the bailout promise is not introduced. We would observe there a moderate increase in net foreign assets of this debtor country. Notwithstanding the borrowing motive implied by the low endowment realization, this country would face high borrowing costs due to high external liabilities, via the function $q\left(y, b^{\prime}\right)$. Hence, it would optimally choose to run current account surpluses, to reduce interest payments on external debt. This saving motive is not present when this country can issue debt to savers in the union at price $\tilde{q}$.

The experience of core countries in the euro area, characterized by higher than average income and wealth, can be analyzed in the model by focusing on the path of net foreign assets chosen by a country with high endowment realization and relatively high net foreign assets. Simulated series for a country at the ninetieth percentile of the wealth distribution and with a realization of the endowment shock two standard deviations above the long-run mean are presented in Figure 9.

The high wealth country optimally runs large current account surpluses in response to the introduction of the bailout promise. In the simulation, this country lets its net foreign asset position improve by 13 percentage points of yearly output in the first 24 quarters after the shock, rising to $8 \%$ of yearly output from a negative position of $-5 \%$. The rise in current account surplus observed in the model is especially large when compared to the one arising in the counterfactual simulation. There, this country would let its assets diminish to finance consumption, running current account deficits. As discussed, features of the allocation with bailout promise induce wealthy countries to increase their savings. Higher returns on union-issued assets and the expectation of future taxes, as 


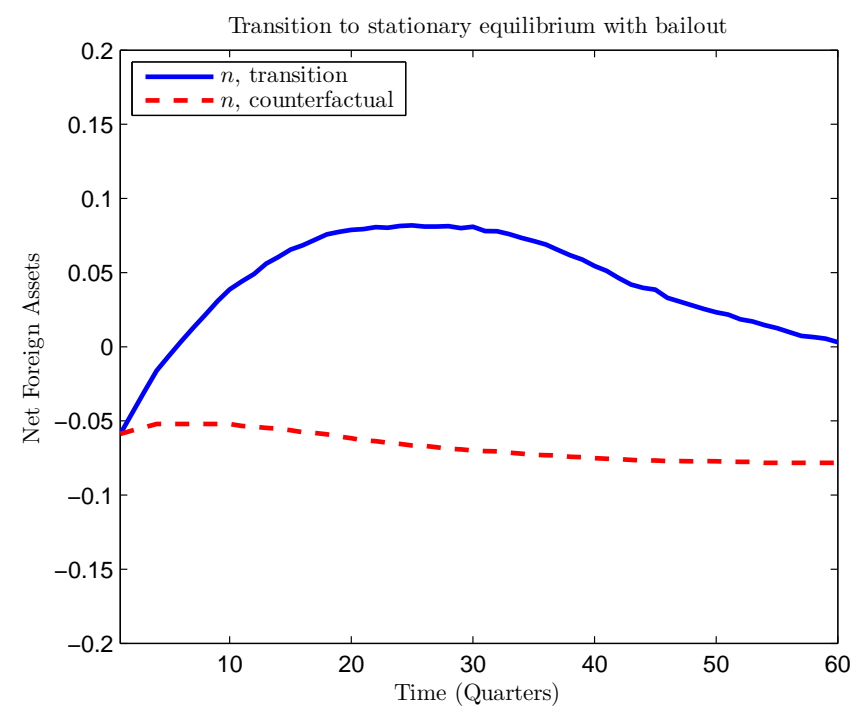

Figure 9: Transition after introduction of bailout promise. Net foreign asset position of a country with low debt and high income (blue, solid line). The red, dashed line displays the counterfactual simulation if no bailout promise is introduced.

needed to finance bailout transfers, induce households in wealthy countries to increase their net savings. This simulated pattern is similar to the one observed in some core euro area economies, where, for instance, a large increase in the net foreign asset position was observed in Germany between 2001 and 2007. Positive current account surpluses also characterized the experience of Austria, Belgium and Netherlands.

The evolution of gross external positions in the model displays a pattern of intermediation of international capital flows, not dissimilar to the one observed in core euro area economies. Figure 10 displays gross asset and liability positions after the introduction of the bailout promise, for the same high wealth country previously considered 62

Two main results emerge. First, we observe an expansion of gross external positions. In the first twenty quarters after the introduction of the bailout promise, gross asset and liability positions both widen in this country. By implication, the amount of gross assets held on the external balance sheet is larger than net foreign assets, as the country leverages by accumulating positive gross liabilities.

Second, gross asset and liability positions differ in terms of counterparty identity and risk. While the former are held by the wealthy country against partners in the union, the latter are issued to $R O W$. In addition, liabilities are always repaid in full, while losses are incurred on risky assets.

Predictions of the model for gross capital flows are quantitatively and qualitatively close to the observation of intermediation that characterized countries in the euro area. In particular, intermediation of gross capital flows was especially prominent in France.

\footnotetext{
${ }^{62}$ I omit here results from the counterfactual simulation. The evolution of gross financial positions would be trivial, as all trade in financial assets occurs with $R O W$ absent a bailout promise. I present again, however, the evolution of net foreign assets during the transition.
} 


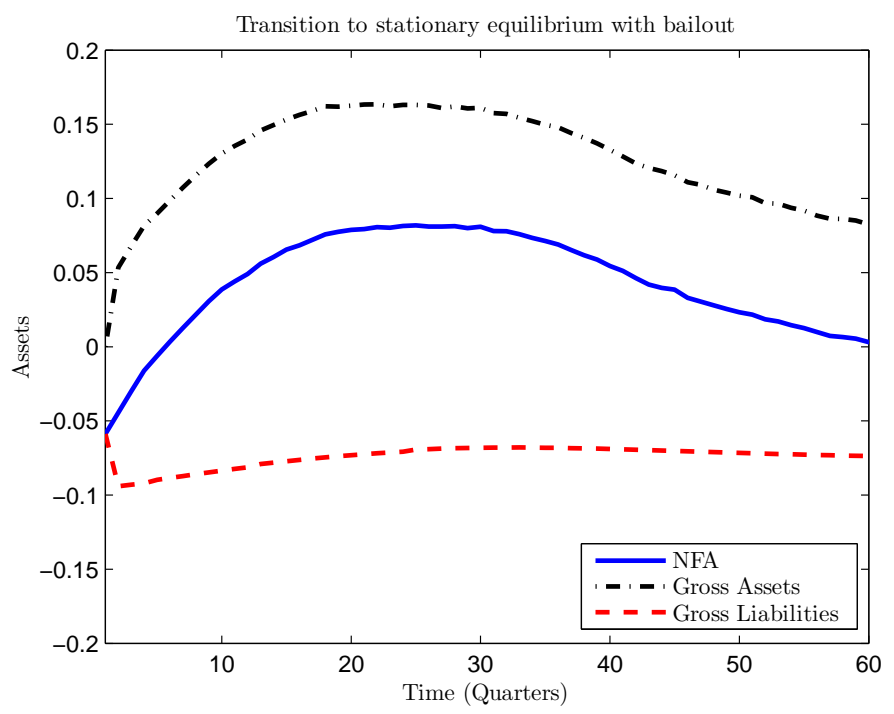

Figure 10: Transition after introduction of bailout promise. Gross foreign asset and liability positions of the low debt, high income country are represented by the black, dashed-dotted line and by the red, dotted line, respectively. The blue, solid line displays the transition for the net foreign asset position.

There, gross assets held against the rest of the euro area rose by 20 percentage points of GDP between 2001 and 2007, as shown in Figure 11. By comparison, gross assets rise by $15 \%$ of yearly output in the model experiment considered. External liabilities against the rest of the world also rose in France, by 30 percentage point of GDP. This amount is significantly larger than the one predicted by the model, corresponding to $8 \%$ of yearly output. Finally, the identity of counterparties of external positions is also similar to the one predicted in the model, with gross assets held against partners in the euro area and gross liabilities issued to the rest of the world.

Debt crisis in the economic union. I will now consider the quantitative effects of a debt crisis taking place in the equilibrium allocation of this model. The main purpose of the experiment conducted here is to analyze how heterogeneous countries in a union are differently affected by a crisis episode, depending on their wealth and on their exposure to trade with union partners. First, I will detail the nature of the experiment considered, and its relationship with the recent sovereign debt crisis. Second, I will present results on the implications of the crisis for aggregate consumption, interest rates and prices in the union. Finally, I will analyze heterogeneous consumption dynamics for large debtors with different export specialization.

To analyze a debt crisis in the economic union I conduct the following experiment. Consider the steady state allocation of the economy with full bailout promise. In this setting, countries in $I$ are tied together by financial linkages in the form of cross-border exposures. The debt crisis is characterized as an unanticipated fall in the value of gross assets held by countries in $I$. The deterioration in asset values can be interpreted as the consequence of a shock inducing an exceptionally large subset of borrowing countries 


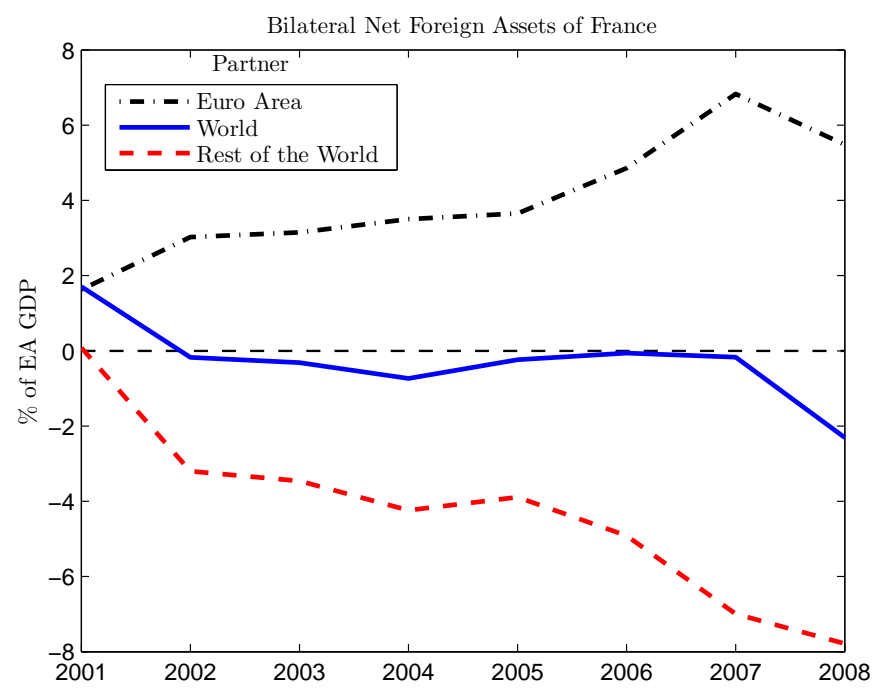

Figure 11: Bilateral international investment positions of France. Net positions against counterparties located in the euro area, in the rest of the world, and global position (World). Source: Waysand, Ross, de Guzman (2010).

to default. After this shock, the economy is left to transition towards its steady state allocation. By modelling a debt crisis in this fashion, I deliberately abstract from direct effects of the crisis on the countries where it originates, focusing instead on transmission and amplification within the economic union. In the simulation presented, the debt crisis is described as a $16 \%$ fall in the aggregate value of gross assets held within the union 63 The transition of aggregate gross assets after the shock is reported in Figure 12. As shown, the value of gross assets held in $I$ reverts endogenously to its steady state value in approximately 50 quarters.

Aggregate consumption in the union falls by $1.6 \%$ in response to the debt crisis, as shown in Figure 13. The magnitude of this fall is comparable with the one observed in the euro area, where real consumption fell by $1.6 \%$ between 2011 and 201364 Two main channels generate the fall in aggregate consumption. First, countries with positive gross assets are directly affected by the shock. As the value of gross assets deteriorates, their wealth falls and consumption falls in response. Second, in general equilibrium, debtor countries are also induced to consume less. As fewer resources are available to borrow from savers within the union, debtors are forced to reduce their liabilities, which they do by reducing consumption.

The interest rate charged on borrowers in the union rises by 280 basis points in the event of the crisis, as shown in Figure 1465 By comparison, the spread between Italian

\footnotetext{
${ }^{63} \mathrm{I}$ assume that the fall in the value of gross assets simply amounts to a net loss in resources, as it is normally the case for non-repayments on risky assets in this economy.

${ }^{64}$ Clearly, the debt crisis in the euro area developed over a longer time horizon than the simple one-time shock considered in this experiment.

${ }^{65}$ The yearly interest rate presented here is defined as $\tilde{r}=\frac{1}{\tilde{q}^{4}}-1$.
} 


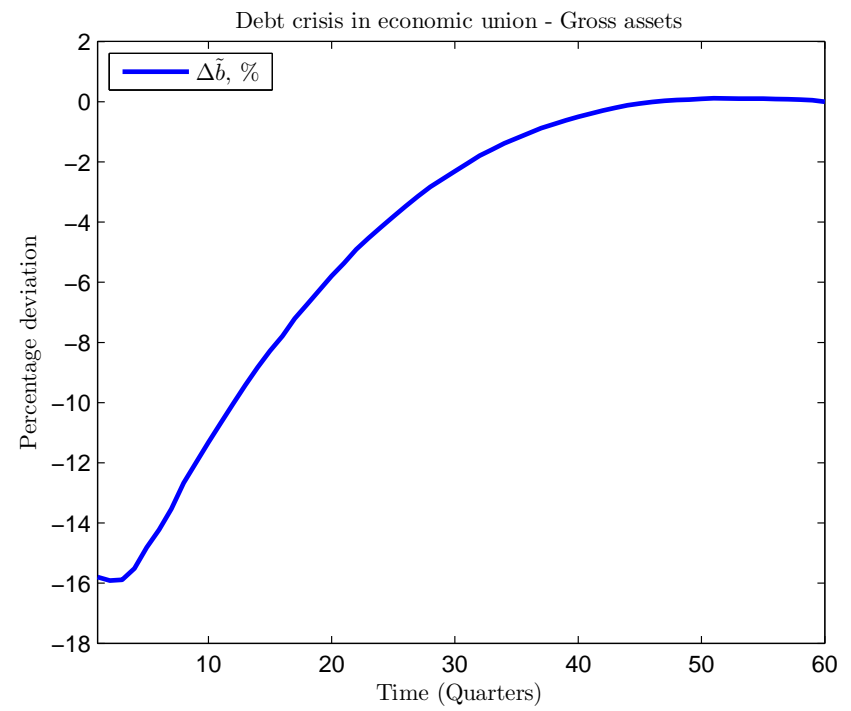

Figure 12: Transition after debt crisis. Value of aggregate gross assets held in $I$, in percentage deviation from steady state.

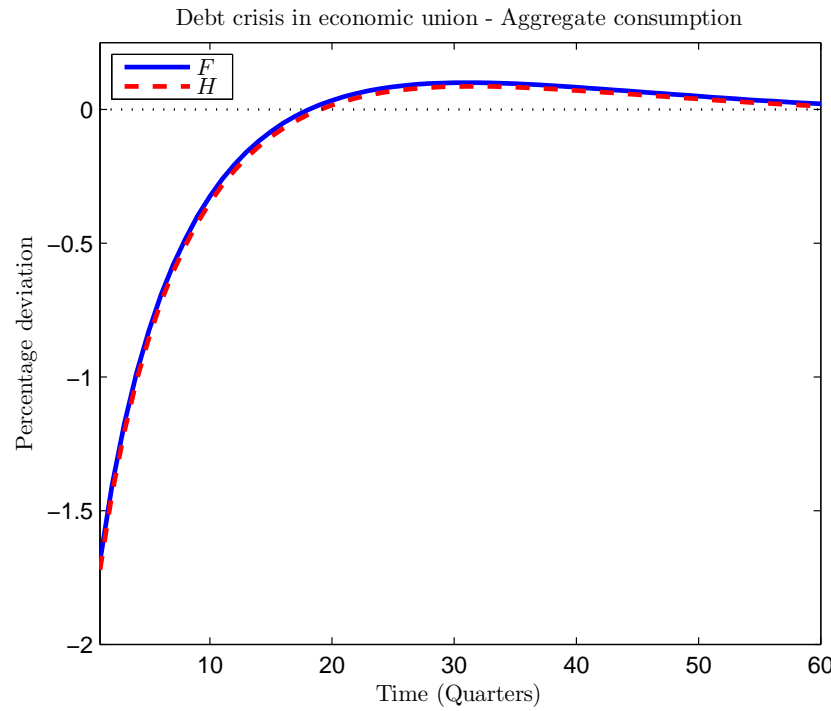

Figure 13: Transition after debt crisis. Aggregate consumption in $H$ and $F$, in percentage deviation from steady state value. 


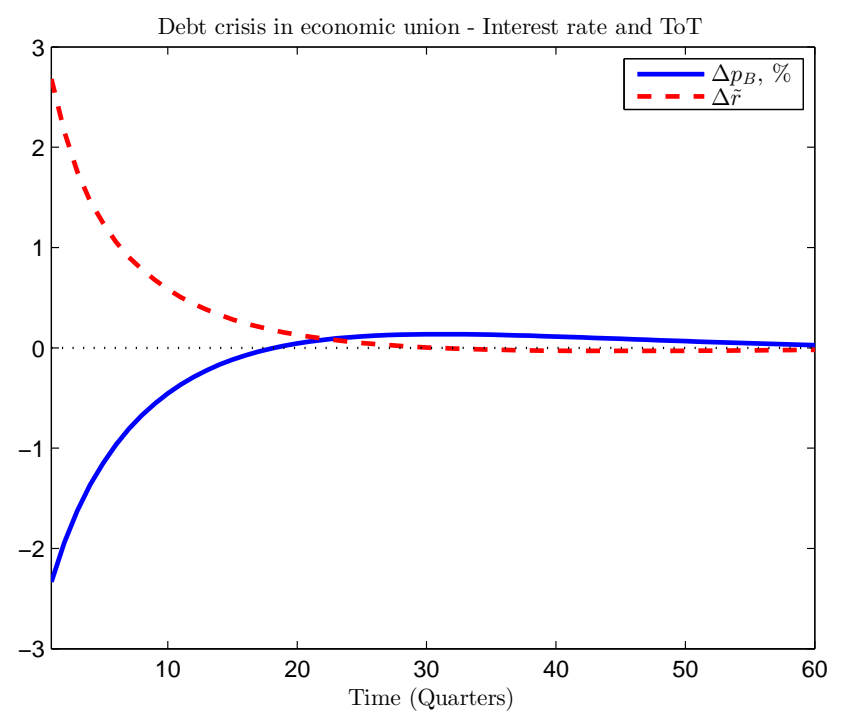

Figure 14: Transition after debt crisis. Relative price of high-transport cost good, $p_{B}$, and interest rate on borrowers, $\tilde{r}$ in percentage deviation and difference, respectively, from steady state values.

and German benchmark bond yields rose by 320 basis points during 2011. The fall in wealth suffered by savers in the union implies that they are willing to purchase a lower amount of risky assets. The rise in the interest rate is the channel ensuring that the market for risky assets clears within $I$, by inducing debtor countries to deleverage and by making assets more attractive for savers.

The contraction in aggregate demand in the union determines a change in relative good prices, causing a fall in $p_{B}$. In response to lower demand in $I$, it is possible for countries in $F$ to costlessly ship their output of $\operatorname{good} A$ to $R O W$, whose demand is unaffected by the crisis. This is not the case for economies in $H$ producing good $B$ : As transport costs hinder trade with $R O W$, when consumption demand is depressed within the union, the relative price of good $B$ has to fall to clear the market within $I 66$ As shown in Figure 14, the relative price of good $B$, falls in this experiment by $2.2 \%$ in response to the debt crisis shock.

The implications of a crisis episode are different across countries with high-debt in $H$ and $F$. I focus here on countries in the poorest percentile of the wealth distribution, with income two standard deviations below the long-run mean. Figure 15 shows the deviation in these countries' consumption between the crisis episode and the counterfactual simulation that would be observed in steady state 67 The high-debt country in $H$ suffers to

\footnotetext{
${ }^{66}$ Note that the supply of goods $A$ and $B$ remains unchanged, as it is not affected by the debt crisis shock.

${ }^{67}$ Similarly to the first experiment considered in this section, the effects of the crisis are heterogeneous across countries in the wealth distribution. In order to compare the simulation arising from the crisis episode with the steady-state counterfactual, I present here the difference between the two series. As before, series displayed are the median from a large number of simulations, corresponding to different draws for sequences of the exogenous process.
} 


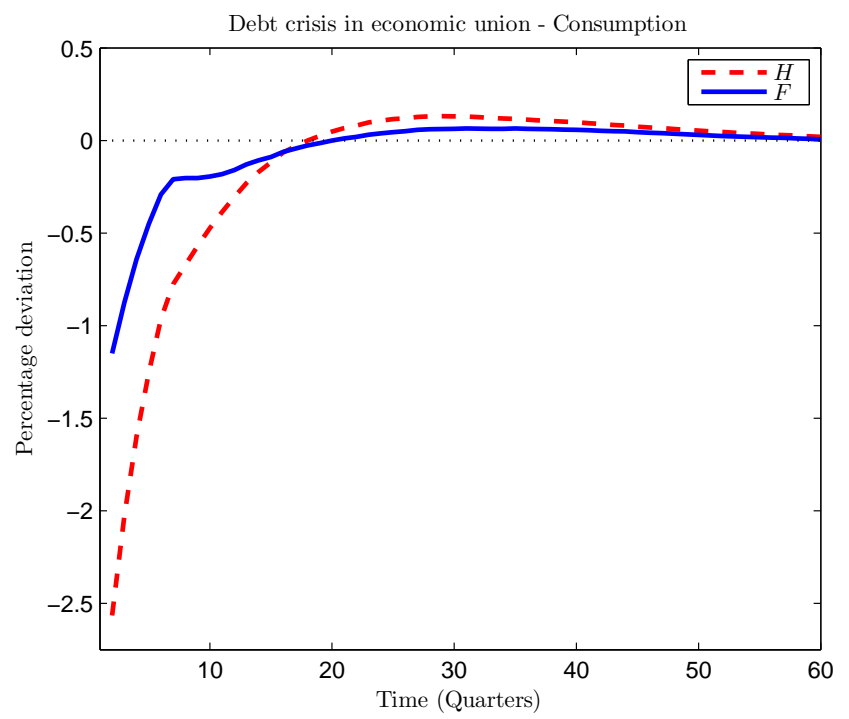

Figure 15: Transition after debt crisis. Consumption of high-debt, low-income economies, specialized in good of type $A$ ( $F$, solid, blue line) or in good of type $B$ ( $H$, dashed, red line). Percentage deviations from counterfactual steady-state simulation.

a greater degree from the crisis, due to its exposure to trade with partners in the union. Due to the crisis, consumption in this country is $2.5 \%$ lower than it would be in steady state. The fall in $p_{B}$ implied by the demand deterioration in the union reduces the value of exports by this country. Being close to the borrowing constraint $\bar{b}$ due to its high debt, this country is unable to let changes in its foreign liabilities absorb the adverse effects of the shock, and the fall in the value of output is reflected in a large contraction in consumption. The high debt country in $F$, on the other hand, experiences a milder reduction in consumption, smaller than the average consumption fall for countries in $I$. As in $H$, consumption of this country is similar to that of a hand-to-mouth agent, due to the presence of the borrowing constraint. Here, however, the fall in $p_{B}$ has a beneficial effect, determining a fall in the price of the aggregate consumption basket. In this country, the severity of a crisis episode is reduced by the availability of cheaper goods, caused by the collapse in aggregate demand in the union.

\section{Concluding remarks}

In the past fifteen years, capital flows in the euro area have been characterized by large current account imbalances and by a distinctive pattern of gross capital flows intermediation. In addition, a sovereign debt crisis led to severe recessions in debtor countries and to weak economic conditions throughout the union. The magnitude of the phenomena in question makes it important to gain a clear understanding of the causes of these facts, especially in light of their potential implications for policy.

This paper shows that the recent experience of capital flows in the European mone- 
tary union can partly be explained by the introduction of policy distortions on trade in financial assets. The pattern of intermediation by core countries of gross capital flows and the widening of current account imbalances within the monetary union can be understood as the result of subsidies on cross-border holdings of assets, introduced in the euro area. The presence of such distortions in various forms has been widely documented in the literature. In addition, removal of currency risk and regulatory harmonization have contributed in inducing cross-border exposures for residents of the euro area 68

I contribute to the literature on capital flows in an economic union by developing a simple theoretical framework. This model allows me to study the implications for net and gross flows of policy distortions on financial assets trade. In addition, I introduce a rich heterogeneous-agents, infinite-horizon model to assess the quantitative importance of the theoretical channels identified by the simpler model.

Two important features of the euro area characterize the model introduced in this paper, the presence of extensive trade in financial assets with the rest of the world and close integration of goods markets within the union. First, by allowing for integration of the union with world financial markets, I am able to analyze the determinants of member countries' gross capital flows. In particular, I can study through the lens of this model the pattern of intermediation observed in the euro area. Second, I analyze the interaction between international capital flows and the pattern of imports and exports of individual countries, by allowing for trade in goods within the union and with the rest of the world. Specifically, I can consider in this framework how countries' specialization and their exposure to trade with union partners determine heterogeneous amplification of a detrimental debt crisis.

Intermediation of international capital flows emerges in my model as agents leverage the subsidy they enjoy on asset holdings. The presence of a subsidy leads residents of an economic union to issue gross liabilities to the rest of the world, in order to finance larger purchases of gross assets. The effects of policy distortions on gross capital flows predicted by the model closely resemble the pattern of intermediation observed in the euro area core, after the inception of the EMU. There, gross asset positions against partners in the periphery rose significantly, funded to a large extent by the creation of gross liability positions against the rest of the world. While the simple theoretical model here introduced clarifies how the introduction of subsidies constitutes a possible explanation for this observation, the infinite-horizon model presented highlights the quantitative relevance of this channel.

The empirical observation of rising current account imbalances is also consistent with predictions of the model for the effects of a subsidy on asset holdings. Importantly, the model generates a rise in the current account surplus of core countries, in response to the introduction of the policy distortion, even when these countries are fully integrated in international financial markets. This effect does not arise mechanically due to a larger deficit in peripheral countries, as it would if precluding trade in assets with the rest of the world. Rather, policy distortions actively induce core countries to increase their savings,

\footnotetext{
${ }^{68}$ See, e.g. Buiter and Sibert (2005), Nouy (2012), Acharya and Steffen (2013), Coeurdacier and Martin (2009), Kalemli-Ozcan, Papaioannou and Peidro (2010), Hale and Obstfeld (2014).
} 
by making assets issued by union partners more attractive.

A perverse feedback effect arises in the event of a sovereign debt crisis, when members of an economic union are tied together by financial as well as by trade linkages. When a debtor defaults on creditor countries that coincide with the main destination of its exports, a fall in the debtor's terms of trade ensues, amplifying the severity of the recession associated with the crisis. This mechanism is likely to have exacerbated the recent recession in peripheral countries of the euro area, as these were significantly exposed to trade with union partners that also constituted important creditors on external liabilities.

In future research, I plan to employ the flexible framework here introduced to consider two closely related issues, the introduction of common monetary policy in the euro area and the different treatment of sovereign and private-sector assets prescribed by financial regulation.

The introduction of common monetary policy has been a distinctive feature of the integration process represented by the EMU. In light of the diverse economic performance observed in countries of the euro area, and the of heterogeneous implications of policy distortions highlighted in this paper, it is interesting to assess whether the presence of common monetary policy has magnified these effects. Fluctuations in demand in the event of a crisis are also heterogeneous in magnitude across union members, and this framework can contribute to our understanding of the stabilizing role of monetary policy in this setting. For instance, changes in the nominal exchange rate of the union against the rest of the world are likely to display a rich pattern of heterogeneous effects across union-member countries, as they differ in terms of gross external positions and trade specialization.

Prescriptions of financial regulation typically allow for different treatment of assets on banks' balance sheets, depending on the identity of their issuers. The prescription of a "zero-risk weight" on sovereign exposures in the Basel II regulatory framework is a notable example of this fact. Regulatory provisions of this type are likely to have had a significant impact on the nature of capital flows received by countries in the euro area periphery, by distorting the composition of flows towards specific counterparties. Recent research has highlighted how the misallocation of resources in the presence of large capital inflows is likely to have led to slow productivity growth in the euro area periphery 69 By extending this framework to explicitly consider private sector agents and endogenous allocation across industrial sectors, it would be possible to further investigate the role of policy distortions and financial regulation in the euro area, analyzing their implications for productivity dynamics.

\footnotetext{
${ }^{69}$ See Aoki, Benigno, Kiyotaki (2009), Reis (2013), Gopinath, Kalemli-Ozcan, Karabarbounis, VillegasSanchez (2015).
} 


\section{A Appendix}

\section{A.1 Description of data and statistics in section 2}

The data used to construct the measures of tradability of output presented in section 2 are drawn from the STructural ANalysis (STAN) and Trade in Value Added (TiVA) databases released by OECD and WTO (OECD 2011b and OECD/WTO, 2015).

I consider data for the year 2005, as that is the last year for which data from both datasets are available for a sufficiently wide sample of countries. The sample consists of all 34 OECD countries with the exclusion of Turkey and Chile, for which STAN data are not fully available. This sample does not include all EU economies: Bulgaria, Croatia, Cyprus, Latvia, Lithuania, Malta and Romania are EU-28 members but not OECD members, hence they are excluded from this sample.

Industrial sectors in my sample correspond to groupings of 2-digits industries from the ISIC Rev.3 Classification. Specifically, these are: Agriculture, hunting, forestry and fishing (01-05), Mining and quarrying (10 - 14), Food products, beverages and tobacco (15 - 16), Textiles, textile products, leather and footwear (17 - 19), Wood, paper, paper products, printing and publishing $(20-22)$, Chemicals and non-metallic mineral products (23 - 26), Basic metals and fabricated metal products (27 - 28), Machinery and equipment, not elsewhere classified (29), Electrical and optical equipment (30 - 33), Transport equipment (34 - 35), Manufacturing not elsewhere classified; recycling (36 - 37), Electricity, gas and water supply (40 - 41), Construction (45), Wholesale and retail trade; Hotels and restaurants $(50-55)$, Transport and storage, post and telecommunication (60 - 64), Financial intermediation (65 - 67), Business services (70 - 74), Other services (75 - 95).

In order to clarify the results described in section 2, I present in Figure 16 data for tradability of output disaggregated at the industrial sector level. Intuitively, services are characterized by low tradability of output, while subsectors of manufacturing, mining and agriculture are characterized by higher than average tradability.

Figure 17 decribes the industrial specialization of the EU economies in the sample, displaying the shares of GVA attributed to groups of industrial sectors ordered according to their tradability. Manufacturing is divided into two groups, with high tradability manufacturing including Textile, Transport equipment, Electrical equipment, Machinery and Chemical products and low tradability manufacturing including Metallic products, Manufacturing not elsewhere classifed, Food and Wood and paper products. Transport services are treated separately from other services due to their higher tradability. Consistently with the evidence presented on tradability of individual sectors, countries displaying higher average tradability are typically characterized by a larger share of the manufacturing sector.

\section{A.2 Proof of Proposition 1}

Consider the case where a risk-neutral agent is the marginal buyer of debt issued by $H$. Given the terminal-period default policy by $H$, the price that the risk-neutral agent is 


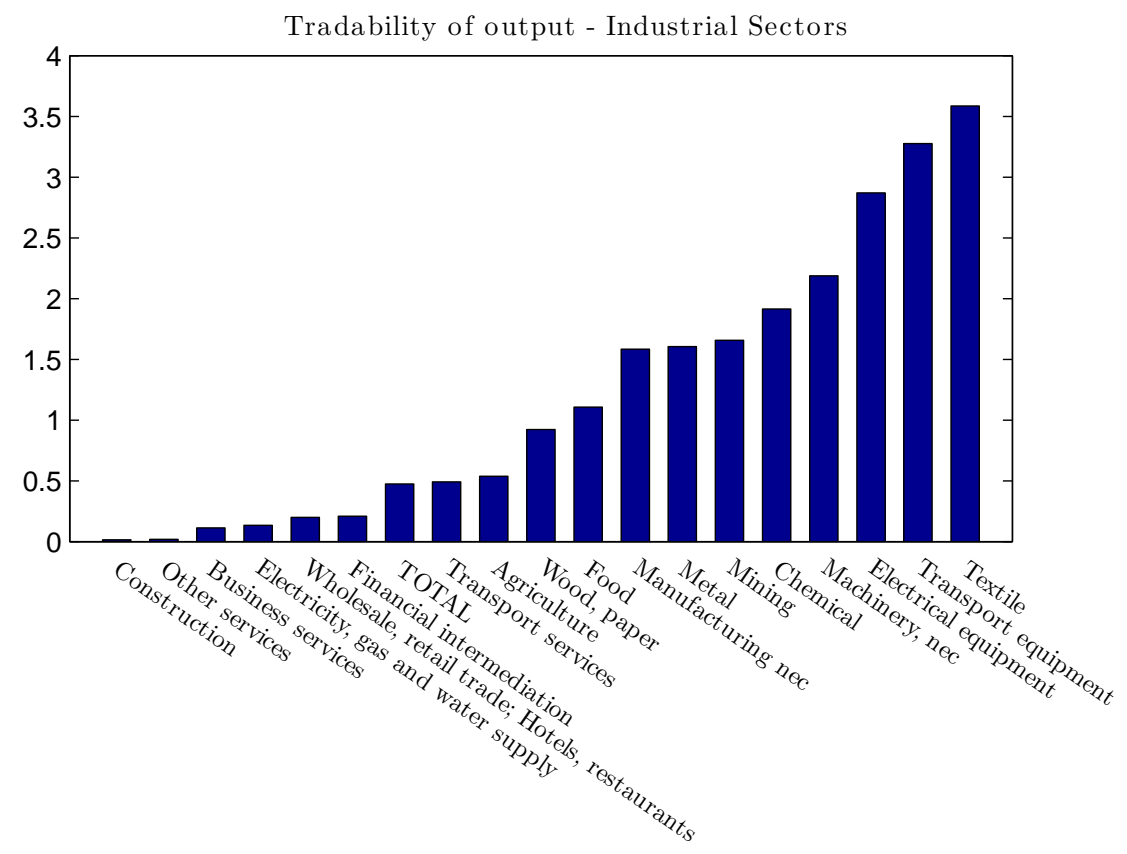

Figure 16: Tradability of output at the industrial sector level. This measure is given by the ratio of total exports and imports attributed to a sector in all countries in the sample, to total GVA of that sector. Data source: OECD STAN and TiVA databases, year 2005.

willing to bid for $b_{H}$ is given by

$$
q_{H}= \begin{cases}\beta & \text { if } b_{H} \in[0, \infty) \\ \pi \beta & \text { if } b_{H} \in[-\hat{\zeta}, 0) \\ 0 & \text { if } b_{H} \in(-\infty,-\hat{\zeta})\end{cases}
$$

The interior solution for $b_{H}$ in $[-\hat{\zeta}, 0)$ to the problem in (5) is given by the solution to the following first-order condition:

$$
\pi \beta \frac{1}{p_{1}} u^{\prime}\left(\frac{y_{A}-\epsilon+p_{B, 1} y_{B}-\pi \beta b_{H}}{p_{1}}\right)=\pi \beta \frac{1}{p_{2, R}} u^{\prime}\left(\frac{y_{A}+p_{B, 2, R} y_{B}+b_{H}}{p_{2, R}}\right) .
$$

where $p_{B, 2, R}$ and $p_{2, R}$ denote prices in the terminal-period state of the world with high output realization, where repayment by $H$ is optimal.

Imposing logarithmic utility, the optimal amount of debt issued by $H$ is given by

$$
b_{H}=-\frac{\epsilon+y_{B}\left(p_{B, 2}-p_{B, 1}\right)}{1+\pi \beta} .
$$

I will restrict attention to cases where $\epsilon>y_{B}\left(p_{B, 1}-p_{B, 2, R}\right)$, where $H$ optimally chooses to issue debt, $b_{H}<0$. This interior solution for $b_{H}$ is optimal if it is preferred by $H$ to all values of $b_{H}$ in $(-\infty,-\hat{\zeta}) \cup[0, \infty)$. 


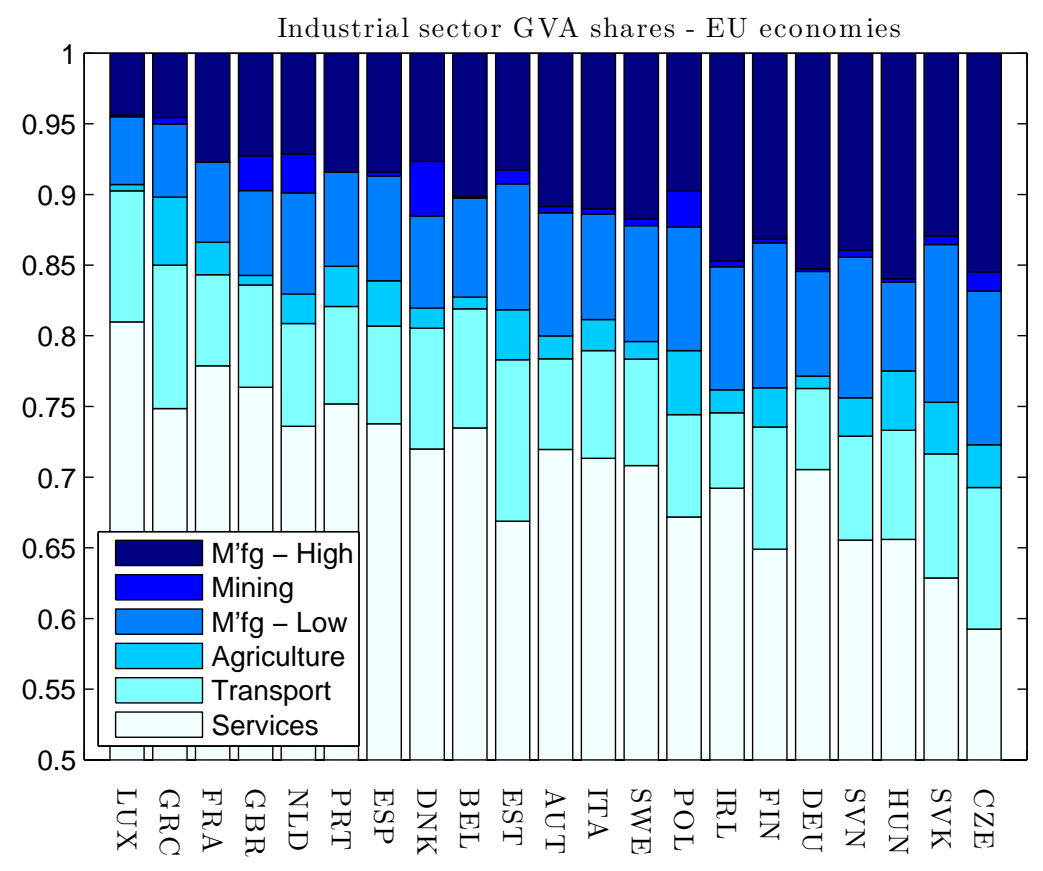

Figure 17: Shares of GVA attributed to broad industrial sectors, ordered by tradability of output. EU economies. Data source: OECD STAN and TiVA databases, year 2005.

Consider now the interior solution with $b_{H}<0$ and $q_{H}=\beta$. Such a solution is characterized by the following first-order condition:

$$
\begin{aligned}
& \beta \frac{1}{p_{1}} u^{\prime}\left(\frac{y_{A}-\epsilon+p_{B, 1} y_{B}-\beta b_{H}}{p_{1}}\right)=\pi \beta \frac{1}{p_{2, R}} u^{\prime}\left(\frac{y_{A}+p_{B, 2, R} y_{B}+b_{H}}{p_{2, R}}\right)+ \\
&(1-\pi) \beta \frac{1}{p_{2, D}} u^{\prime}\left(\frac{y_{A, L}+p_{B, 2, D} y_{B}+b_{H}}{p_{2, D}}\right) .
\end{aligned}
$$

where $p_{B, 2, D}$ and $p_{2, D}$ denote prices in the terminal-period state of the world with low output realization. Note that, for $b_{H} \geq 0$, default never occurs. Imposing logarithmic utility, the first-order condition becomes:

$$
\begin{aligned}
& \frac{1}{y_{A}-\epsilon+p_{B, 1} y_{B}-\beta b_{H}}=\pi \frac{1}{y_{A}+p_{B, 2, R} y_{B}+b_{H}}+ \\
&(1-\pi) \frac{1}{y_{A, L}+p_{B, 2, D} y_{B}+b_{H}} .
\end{aligned}
$$

Such a condition cannot be satisfied by a value of $b_{H}>0$ whenever the initial-period output realization is sufficiently low:

$$
\epsilon>y_{A}+p_{B, 1} y_{B}-\left[\pi \frac{1}{y_{A}+p_{B, 2, R} y_{B}}+(1-\pi) \frac{1}{y_{A, L}+p_{B, 2, D} y_{B}}\right]^{-1} .
$$


Let us now consider the corner solution $b_{H}=0$. Welfare of the representative household is given in this case by :

$$
\begin{aligned}
V_{H, \text { corner }}= & \log \left(y_{A}-\epsilon+y_{B} p_{B, 1}\right)-\log \left(p_{1}\right) \\
& +\pi \beta\left[\log \left(y_{A}+y_{B} p_{B, 2, R}\right)-\log \left(p_{2, R}\right)\right]+(1-\pi) \beta \log \left(\frac{y_{A, L}+y_{B} p_{B, 2, D}}{p_{2, D}}\right)
\end{aligned}
$$

Compare this with welfare under the interior solution for $b_{H}$ in $[-\hat{\zeta}, 0)$, imposing $\log$ utility:

$$
\begin{aligned}
V_{H, \text { risky-debt }}= & -\log \left(p_{1}\right)-\pi \beta \log \left(p_{2, R}\right) \\
& +(1+\pi \beta)\left[\log \left(y_{A}-\frac{\epsilon}{1+\pi \beta}+\frac{1}{1+\pi \beta} y_{B} p_{B, 1}+\frac{\pi \beta}{1+\pi \beta} y_{B} p_{B, 2, R}\right)\right] \\
& +(1-\pi) \beta \log \left(\frac{y_{A, L}+y_{B} p_{B, 2, D}}{p_{2, D}}\right) .
\end{aligned}
$$

Removing identical terms, and ignoring differences in good prices across the two solutions, due to price-taking behaviour, the risky-debt choice is preferred to the corner solution if and only if

$$
\begin{aligned}
(1+\pi \beta) \log \left(y_{A}-\right. & \left.\frac{\epsilon}{1+\pi \beta}+\frac{1}{1+\pi \beta} y_{B} p_{B, 1}+\frac{\pi \beta}{1+\pi \beta} y_{B} p_{B, 2, R}\right)> \\
& \log \left(y_{A}-\epsilon+y_{B} p_{B, 1}\right)+\pi \beta \log \left(y_{A}+y_{B} p_{B, 2, R}\right)
\end{aligned}
$$

noting that

$$
\begin{gathered}
y_{A}-\frac{\epsilon}{1+\pi \beta}+\frac{1}{1+\pi \beta} y_{B} p_{B, 1}+\frac{\pi \beta}{1+\pi \beta} y_{B} p_{B, 2, R}= \\
\frac{1}{1+\pi \beta}\left(y_{A}-\epsilon+y_{B} p_{B, 1}\right)+\frac{\pi \beta}{1+\pi \beta}\left(y_{A}+y_{B} p_{B, 2, R}\right) .
\end{gathered}
$$

this condition is satisfied due to concavity of the logarithm function and Jensen's inequality.

It is trivial to rule out choices for $b_{H}$ in $(-\infty,-\hat{\zeta})$. Given $q_{H}=0$, such choices are dominated by setting $b_{H}=0$. While the same amount of resources is obtained in the initial period, i.e. zero, by choosing $b_{H}<-\hat{\zeta}$ a positive output cost of default is suffered with positive probability in the terminal period.

Suppose an agent were willing to bid $q_{H}>\pi \beta$ for $b_{H} \in(-\hat{\zeta}, 0), q_{H}=0$ for $b_{H}<-\hat{\zeta}$ and $q_{H}=\beta$ for $b_{H} \geq 0$. A fortiori, it will still be optimal for $H$ to issue $b_{H}$ in the $(-\hat{\zeta}, 0)$ interval, as the value of this choice improves, while the value of the alternatives is unchanged.

The above proves that a risky borrowing choice is preferred to all other choices when

$\epsilon>\min \left\{y_{B H}\left(p_{B, 1}-p_{B, 2}\right), y_{A}+p_{B, 1} y_{B}-\left[\pi \frac{1}{y_{A}+p_{B, 2, R} y_{B}}+(1-\pi) \frac{1}{y_{A, L}+p_{B, 2, D} y_{B}}\right]^{-1}\right\}$. 
This condition is function of good prices that are determined in general equilibrium and, in general, it must be verified on a case-by-case basis. In the special case where $p_{B}$ is constant across periods and states of the world, for example being determined in $R O W$ due to the absence of transport costs, $\tau=0$, the condition simplifies to

$$
\epsilon>(1-\pi)\left(y_{A}-y_{A, L}\right) \frac{y_{A}+p_{B} y_{B}}{\pi y_{A, L}+(1-\pi) y_{A}+p_{B} y_{B}} .
$$

\section{A.3 Optimization problem in ROW}

The $R O W$ is inhabited by a risk-neutral representative household enjoying utility from consumption of goods of type $A$ and $B$.

The problem faced by the representative household in $R O W$ is the following:

$$
\begin{aligned}
& \begin{array}{l}
\max _{c_{1}^{R O W}, c_{A, W}^{R O W}, c_{B, 1}^{R O W},} c_{1}^{R O W}+\beta \mathbb{E} c_{2}^{R O W} \\
c_{2}^{R O W}, c_{A, 2}^{R O W}, c_{B, 2}^{R O W W}, \\
b_{R O W}, b_{H, R O W} \geq 0
\end{array} \\
& \text { s.t. } c_{t}^{R O W}=\left(c_{A, t}^{R O W}\right)^{a}\left(c_{B, t}^{R O W}\right)^{1-a} \text {, } \\
& p_{1}^{R O W} c_{1}^{R O W}=y_{A}^{R O W}+p_{B, 1}^{R O W} y_{B}^{R O W}+q_{R O W} b_{R O W}-q_{H} b_{H, R O W} \text {, } \\
& p_{2}^{R O W} c_{2}^{R O W}=y_{A}^{R O W}+p_{B, 2}^{R O W} y_{B}^{R O W}-b_{R O W}+(1-D) b_{H, R O W} \text {, }
\end{aligned}
$$

where I allow relative prices and price indices in $R O W$, to differ from those prevailing in $H$ and $F$. All other variables have their intuitive meaning, in particular, $b_{H, R O W}$ denotes the amount of assets issued by $H$ and purchased by $R O W$ and $b_{R O W}$ denotes the amount of risk-free assets that are issued by $R O W$.

\section{A.4 Crisis amplification in $H$}

Consider terminal-period consumption in $H$ in the crisis state where it receives a low amount of good $A$ endowment. This is given by

$$
c=\frac{y_{A, L}+p_{B} y_{B}}{p} .
$$

Denoting with subscripts $I$ and $N I$ allocations in the intermediation and non-intermediation scenarios, respectively, the crisis is amplified in $H$ in presence of intermediation when

$$
\frac{c_{I}}{c_{N I}}=\frac{p_{N I}}{p_{I}} \frac{y_{A, L}+p_{B, I} y_{B}}{y_{A, L}+p_{B, N I} y_{B}}<1
$$

It is easy to see that this condition holds when specialization in $B \operatorname{good}$ in $H$ is extreme, namely when $y_{A, L}=0, y_{B}>0$. In this case,

$$
\frac{c_{I}}{c_{N I}}=\frac{p_{N I}}{p_{I}} \frac{p_{B, I}}{p_{B, N I}}={\frac{p_{B, I}}{p_{B, N I}}}^{a}
$$


Default by $H$ liabilities owed to $F$ rather than to $R O W$ causes lower wealth in the union in the intermediation scenario. The ensuing lower price of the high-transport cost good $B$ is unambiguously detrimental to consumption in $H$, when this economy displays extreme specialization in this type of good, as stated in (15). Consider now the opposite case where $H$ is extremely specialized in $\operatorname{good} A, y_{A, L}>0, y_{B}=0$. Now,

$$
\frac{c_{I}}{c_{N I}}=\frac{p_{N I}}{p_{I}}={\frac{p_{B, I}}{p_{B, N I}}}^{a-1}
$$

In this event, a fall in the relative price of good $B$ implies an appreciation of the terms of trade and, thanks to cheaper imports of good $B$, intermediation dampens the severity of the crisis in $H$. Finally, consider the general case where both $y_{A, L}>0$ and $y_{B}>0$ :

$$
\frac{c_{I}}{c_{N I}}<1 \leftrightarrow \frac{y_{A, L}+p_{B, I} y_{B}}{y_{A, L}+p_{B, N I} y_{B}}<\frac{p_{I}}{p_{N I}}
$$

Noting that $\frac{p_{I}}{p_{N I}}=\left(\frac{p_{B, I}}{p_{B, N I}}\right)^{1-a}$, taking logs and making use of the fact that $\log (1+x) \approx x$, at first order, the condition above reduces to

$$
\frac{\left(p_{B, I}-p_{B, N I}\right) y_{B}}{y_{A, L}+p_{B, N I} y_{B}}<(1-a) \frac{p_{B, I}-p_{B, N I}}{p_{B, N I}}
$$

Imposing $p_{B, N I}=\frac{y_{A, L}+y_{A}^{*}+b_{F, N I}}{y_{B}+y_{B}^{*}}$, this reduces to the condition on relative abundance of good $B$ stated in (17):

$$
\frac{y_{B}}{y_{B}+y_{B}^{*}}>\frac{y_{A, L}}{y_{B}+y_{B}^{*}} y_{A, L}+y_{A}^{*}+b_{F, N I}
$$

\section{A.5 Model with homogeneous consumption good}

This appendix presents a simplified version of the model in Section [3. In this version, all countries consume and are endowed with only one type of consumption good, freely tradable across all country pairs. This version of the model allows for a simpler analysis of the effects of policy distortions on intermediation of gross flows and current account imbalances. In addition, it can serve as a useful benchmark against which to compare the two-good model. This is especially true with regard to results on the amplification of a crisis due to the interaction between financial and trade linkages among members of a union of countries. The reader is referred to Section 3 for a full presentation of the model, as only major departures from the two-good version of the model will be described here.

Lifetime utility of households in $H$ and $F$ is given by (11), where $c_{t}$ now simply denotes consumption of a homogeneous consumption good. The homogeneous consumption good is the numeraire of this simplified model economy.

$H$ receives in the initial period an endowment of good given by

$$
y_{1}=y-\epsilon
$$


where $\epsilon$ denotes the amount by which the initial-period endowment falls short of a longrun value, which is now given by $y$. In the terminal period, the endowment received by $H$ is subject to uncertainty, as in the two-good case:

$$
y_{2}=\left\{\begin{array}{ll}
y & \text { w.p. } \pi \\
y_{L} & \text { w.p. } 1-\pi .
\end{array} .\right.
$$

Again, the fiscal authority in $H$ cannot commit to repay debt in the terminal period, and default costs are defined as in the two-good case, (4).

The problem faced by the fiscal authority in $H$ is now the following:

$$
\begin{aligned}
V_{H}(\epsilon)= & \max _{\substack{b_{H}, c_{1}, c_{2}, D \in\{0,1\}}} u\left(c_{1}\right)+\beta \mathbb{E}\left[u\left(c_{2}\right)\right] \\
\text { s.t. } & c_{1}+q_{H} b_{H}=y-\epsilon, \\
& c_{2}=y_{2}+-\left[D \zeta-(1-D) b_{H}\right],
\end{aligned}
$$

The solution to this problem can be described by the optimality condition:70

$$
q_{H} u^{\prime}\left(c_{1}\right)=\beta \pi u^{\prime}\left(c_{2, R}\right) .
$$

The problem solved in $F$ is the following:

$$
\begin{aligned}
V_{F}(\epsilon)= & \max _{\substack{c_{1}^{*}, c_{2}^{*}, b_{F}, b_{H F} \geq 0}} u\left(c_{1}^{*}\right)+\beta \mathbb{E}\left[u\left(c_{2}^{*}\right)\right] \\
\text { s.t. } & c_{1}^{*}+q_{F} b_{F}+q_{H} b_{H F}=y^{*}, \\
& c_{2}^{*}=y^{*}+b_{F}+\left[D\left(\xi b_{H F}-T\right)+(1-D) b_{H F}\right],
\end{aligned}
$$

and it can be summarized by the following system of first-order condition 71 :

$$
\begin{aligned}
& q_{F} u^{\prime}\left(c_{1}^{*}\right)=\beta \mathbb{E}\left[u^{\prime}\left(c_{2}^{*}\right)\right] \\
& q_{H}=q_{F}-\beta(1-\pi)(1-\xi) \frac{u^{\prime}\left(c_{2, D}^{*}\right)}{u^{\prime}\left(c_{1}^{*}\right)} .
\end{aligned}
$$

The $R O W$ is again a large, risk-neutral agent, with subjective discount factor $\beta$.

Intermediation of gross capital flows and current account imbalances. The one-good framework allows for a simple description of trade in financial assets in this model. Consider first the case where no bailout promise is offered to households in $F$,

\footnotetext{
${ }^{70}$ As in the two-good case, this optimality condition only holds in the interior solution, when it is optimal for $H$ to issue debt carrying positive but not certain default probability, see Proposition 1.

${ }^{71}$ Again, as in the two-good case, this is only true in cases where $H$ issues risky debt and gross assets purchased by $F$ are positive, $b_{H} \in(-\hat{\zeta}, 0)$ and $b_{H F}>0$.
} 
$\xi=0 . \quad F$ issues risk-free debt to $R O W$ at price given by $q_{F}=\beta$. The price of $H$ issued assets consistent with pricing by households in $F$ has to satisfy the system in (44). Imposing log-utility, the period budget constraints and $q_{F}=\beta$, this is given by:

$$
\begin{aligned}
\frac{1}{y-\beta b_{F}-q_{H} b_{H F}} & =\pi \frac{1}{y+b_{F}+b_{H F}}+(1-\pi) \frac{1}{y+b_{F}} \\
q_{H, F} & =\beta-\beta(1-\pi) \frac{y+\beta b_{F}+q_{H} b_{H F}}{y+b_{F}} .
\end{aligned}
$$

The price of $H$-assets consistent with the solution to the problem in $F$ is higher than the price at which $R O W$ is willing to buy these assets, $q_{H, F}>\beta \pi$, if and only if

$$
\frac{y+\beta b_{F}+q_{H} b_{H F}}{y+b_{F}}<1 .
$$

The solution to 45 implies that this inequality cannot be satisfied for $b_{H F}>0$. Hence, $F$ is not willing to purchase any positive amount of assets issued by $H$ at price $q_{H, F} \geq \beta \pi$. From the above, it follows that the marginal buyer of debt issued by $H$ is $R O W$ if no bailout promise is offered to households in $F$, and that no amount of $H$-issued assets is purchased by $F$. In addition, no liabilities are issued by $F$, as $b_{F}=0, b_{H F}=0$ constitutes a solution to (44) when $\xi=0$.

I have established that in the absence of a bailout promise, $\xi=0$, the price of $H$-issued assets has to be consistent with pricing by $R O W$ and it is therefore given by $q_{H}=\beta \pi$. From the optimality condition in $H$, it follows that assets issued satisfy

$$
b_{H}=-\frac{\epsilon}{1+\beta \pi} .
$$

Intuitively, issuance of debt delivers insurance against the initial-period endowment shock, $\epsilon$.

Consider now the case where a full bailout promise is offered to households in $F$, $\xi=1$. It is trivial to show that the price of $H$-issued assets that is consistent with optimality in $F$, (44), is given by $q_{H}=\beta$, making $F$ the marginal and sole buyer of these assets. Given this price, the amount of assets issued by $H$ is given by

$$
b_{H}=-\frac{\pi \epsilon+(1-\pi) y}{1+\beta \pi},
$$

showing that $H$ benefits from the higher price of its own debt by running a wider current account deficit 72

$F$ finances purchases of $H$-issued assets with own resources and by borrowing from $R O W$. The amount of liabilities issued by $F$ to $R O W$ follows from the solution to (44), given $q_{H}=\beta$ and $b_{H}=-b_{H F}$. It can be shown that $\frac{b_{F}}{b_{H}}$ ranges between $\frac{-\beta}{1+\beta}$ for $\pi=0$ and -1 , for $\pi=1$. Finally, to the extent that $\left|\frac{b_{F}}{b_{H}}\right|<1, F$ acts as a net saver, financing part of its gross asset purchases with own resources. The presence of a bailout promise, then, induces $F$ to run a current account surplus, contributing to wider current account imbalances in the union of $H$ and $F$.

\footnotetext{
${ }^{72}$ This is clearly true to the extent that $\epsilon<y$.
} 
Crisis transmission and amplification. The analysis of a crisis event is extremely simple in this one-good framework. In the terminal-period crisis state, consumption in $F$ is given by

$$
c_{2, D}^{*}=y^{*}+b_{F} .
$$

The analysis above showed that $b_{F} \neq 0$ if and only if $\xi>0$ : A bailout promise induces the creation of gross external positions in $F$. In the absence of the bailout promise, the crisis would not be transmitted to $F$, as $b_{F}=0$ in that case. When $F$ issues gross external liabilities to purchase risky gross assets issued by $H$, its consumption in the crisis state is adversely affected due to default by $H$.

In the absence of fluctuations in goods relative prices, financial linkages between $H$ and $F$ are not sufficient to deliver amplification of the crisis in $H$. In $H$, terminal-period consumption in the crisis state is simply given by

$$
c_{2, D}=y_{L} .
$$

In the absence of intra-temporal trade and unlike in the two-good framework, consumption in $H$ in a crisis is independent of the identity of its external creditors.

\section{A.6 Proof of Proposition 2}

Consider the allocation with $\xi=0, \pi \rightarrow 0$. Consumption by $H$ in financial autarky is given by $c_{1}=y-\epsilon, c_{2, D}=y_{L}, c_{2, R}=y$, noting that the repayment state is realized with zero probability in the limit. In the limit, welfare in $H$ is given by

$$
V_{H}^{\xi=0}(\epsilon)=\log (y-\epsilon)+\beta \log \left(y_{L}\right) .
$$

Consumption by $F$ is given by $c_{s}^{*}=y^{*}$ in all periods and states $s$. Welfare in $F$ is

$$
V_{F}^{\xi=0}(\epsilon)=(1+\beta) \log \left(y^{*}\right) .
$$

Under the bailout allocation, borrowing by $H$ is bounded in the limit by the amount of resources available in the repayment state, $b_{H}=-y$. Consumption is given by $c_{1}=2 y-\epsilon$, $c_{2, D}=y_{L}$ and $c_{2, R} \rightarrow 0$. Using the fact that $\lim _{x \rightarrow 0} x \log (x)=0$, welfare in $H$ tends to

$$
V_{H}^{\xi=1}(\epsilon)=\log (2 y-\epsilon)+\beta \log \left(y_{L}\right) .
$$

As established in (14) borrows $b_{F}=\frac{\beta}{1+\beta} b_{H}=-\frac{\beta}{1+\beta} y$ to finance asset purchases when $\pi=0$. In the limit for $\pi=0$, consumption is equalized across the initial period and terminal period default state: $c_{1}^{*}=c_{2, D}^{*}=y^{*}-\frac{\beta}{1+\beta} y$. Welfare in $F$ in the bailout allocation is then given by

$$
V_{F}^{\xi=1}(\epsilon)=(1+\beta) \log \left(y^{*}-\frac{\beta}{1+\beta} y\right) .
$$

Note that the change in $F$ welfare induced by the bailout promise is independent of $\epsilon$ :

$$
V_{F}^{\xi=1}(\epsilon)-V_{F}^{\xi=0}(\epsilon)=(1+\beta) \log \left(1-\frac{\beta}{1+\beta} \frac{y}{y^{*}}\right) .
$$


The change in welfare in $H$ is instead increasing in $\epsilon$ :

$$
V_{H}^{\xi=1}(\epsilon)-V_{H}^{\xi=0}(\epsilon)=\log \left(\frac{2-\epsilon / y}{1-\epsilon / y}\right)
$$

Hence, the change in union welfare induced by the bailout promise, $V^{\xi=1}(\epsilon)-V^{\xi=0}(\epsilon)$, is increasing in $\epsilon$. Note that this change tends to infinity for $\epsilon \rightarrow y$. For $\epsilon=0, V^{\xi=1}(\epsilon)-$ $V^{\xi=0}(\epsilon)<0$ under the following condition for $y / y^{*}$ and $\beta$ :

$$
\left(1-\frac{\beta}{1+\beta} \frac{y}{y^{*}}\right)^{1+\beta}<\frac{1}{2} .
$$

By continuity of $V_{H}^{\xi=1}(\epsilon)-V_{H}^{\xi=0}(\epsilon)$ and the intermediate value theorem, it can be shown that there exist a value $\bar{\epsilon} \in(0, \infty)$ such that $V^{\xi=1}(\bar{\epsilon})-V^{\xi=0}(\bar{\epsilon})=0$ and $V^{\xi=1}(\epsilon)-$ $V^{\xi=0}(\epsilon)>0$ for $\epsilon>\bar{\epsilon}$.

\section{A.7 Infinite-horizon model, solution method}

The solution of this model is obtained by a numerical algorithm related to the one proposed by Guerrieri and Lorenzoni (2011), also employed by Fornaro (2014) in a model of external debt.

Solution for the equilibrium of the economy with no bailout promises is relatively simple. The risk-free real interest rate is exogenous in this model, as determined in $R O W$. I need to solve for the endogenous price of good $B, p_{B}$, which is determined in general equilibrium within the union $I$. To solve for the steady state of this model economy, I first need to obtain optimal policy functions of individual countries for net foreign assets, $b^{\prime}(y, n)$. I discretize the state space on a grid for $y$ and $n$, and I solve for the policy functions by iterating on the Euler equation that follows from the problem of individual countries, 33, given an initial guess for $p_{B}, p$. The price at which individual countries issue debt follows from $q^{R O W}$ and from the function determining $\pi$, 36. Having obtained policy functions for net foreign asset accumulation, I update the distribution of net foreign assets in the economic union, until its convergence. Given distribution and policy functions, I solve for aggregate consumption in $I$ and I check whether the market for good $B$ clears within the union. If not, I update the for $p_{B}$ and $p$ I repeat this procedure until market clearing. The distribution obtained upon convergence of $p_{B}$ is the steady state distribution of this model economy.

The algorithm I implement to solve for the steady state equilibrium of the economy with a full bailout promise is an extension of the one above presented. In addition to the distribution of net foreign asset and to the relative price $p_{B}$, I need to solve for the equilibrium price of union issued assets, $\tilde{q}$, and for the function determining the amount of tax paid by the representative household in gross saving countries. Again, I discretize the state space and I introduce an initial guess for aggregate variables, $\tilde{q}, p_{B}$ and taxes. Given the initial guesses, I iterate on the Euler equation of gross savers and borrowers to determine their policy functions for external positions, $\tilde{b}^{\prime}(y, n, N), b^{\prime}(y, n, N)$ and for 
the rule determining whether each country is a borrower or a gross saver, $\varpi$. Again, I use the policy functions to obtain a stationary distribution of net foreign assets. I now need to ensure that the market for good $B$ and the market for assets issued within the union clear. In addition, the function determining taxes in gross saver economies has to be consistent with the amount of bailout transfers paid by in each period to holders of gross assets. To this purpose, I make use of the result that all assets issued within the union are perfect substitutes, thanks to the full bailout promise. I can impose that the portfolio of assets held by all gross saver countries is the market portfolio. By implication, losses on gross assets due to default are equal in each country to the aggregate fraction of non-repayments on liabilities, determined by the function $\pi$. Taxes paid in each period by the representative household in gross saver economies are then a constant fraction of holdings of gross assets. I iterate the above procedure until convergence of the net foreign asset distribution, $p_{B}, \tilde{q}$ and of the tax rate paid on gross assets.

Finally, I employ a standard algorithm to compute dynamic transitions after shocks in the two quantitative exercises. I introduce an initial guess for the path of aggregate variables for a large number of periods. Assuming that the economy will be in steady state in the final period, I solve the problem of individual countries backwards, given the guess for aggregate variables. In the initial period, the net foreign asset distribution of the economy is either the one of the steady state with no bailout promises, in the first exercise considered, or in the that arises after the shock to gross assets caused by the debt crisis. Starting from the initial period, I update the distribution forwards, given the policy functions obtained. In general, markets will not clear along the transition, and I update guesses for prices accordingly. Given the new guess, I repeat the procedure, until convergence of prices. Importantly, I need to check that in the final period of the transition the equilibrium of the economy is indeed given by the steady state one. 


\section{References}

[1] Acharya, Viral V. and Sascha Steffen, (2013). The "Greatest" Carry Trade Ever? Understanding Eurozone Bank Risks, NBER Working Papers 19039, National Bureau of Economic Research.

[2] Aguiar, Mark; Amador, Manuel; Farhi, Emmanuel; Gopinath, Gita, (2015). Coordination and Crisis in Monetary Unions, Staff Report 511, Federal Reserve Bank of Minneapolis.

[3] Altavilla, Carlo; Domenico Giannone; Michele Lenza, (2014). The financial and macroeconomic effects of OMT announcements, Working Paper Series 1707, European Central Bank.

[4] Anderson, James E.; Eric van Wincoop, (2004). Trade Costs, Journal of Economic Literature, American Economic Association, vol. 42(3), pages 691-751, September.

[5] Aoki, Kosuke, Gianluca Benigno, Nobuhiro Kiyotaki, (2010). Adjusting to Capital Account Liberalization, CEPR Discussion Papers 8087, C.E.P.R.

[6] Arellano, Cristina, (2008). Default Risk and Income Fluctuations in Emerging Economies, American Economic Review, vol. 98(3), pages 690-712, June.

[7] Arellano, Cristina, and Yan Bai (2014). Linkages across Sovereign Debt Markets, Research Department Staff Report 491, Federal Reserve Bank of Minneapolis.

[8] Ayres, Joao Luiz; Gaston Navarro; Juan Pablo Nicolini, Pedro Teles, (2015). Sovereign Default: The Role of Expectations. No. 723. Research Department Working Paper 723, Federal Reserve Bank of Minneapolis.

[9] Backus, David; Patrick J. Kehoe; Finn E. Kydland, (1994). Dynamics of the Trade Balance and the Terms of Trade: The J-curve. American Economic Review vol.84(1), pages 84-103.

[10] Benigno, Gianluca; Huigang Chen; Christopher Otrok; Alessandro Rebucci; Eric R. Young, (2013). Financial crises and macro-prudential policies, Journal of International Economics, vol. 89(2), pages 453-470.

[11] Benigno, Pierpaolo and Federica Romei, (2014). Debt deleveraging and the exchange rate, Journal of International Economics, vol. 93(1), pages 1-16.

[12] Betts, Caroline M. and Timothy J. Kehoe, (2001), Tradability of Goods and Real Exchange Rate Fluctuations, Federal Reserve Bank of Minneapolis, Research Department Staff Report.

[13] Bianchi, Javier (2011). Overborrowing and Systemic Externalities in the Business Cycle, American Economic Review, American Economic Association, vol. 101(7), pages 3400-3426, December. 
[14] Broner, Fernando; Aitor Erce; Alberto Martin; Jaume Ventura, (2014) Sovereign debt markets in turbulent times: Creditor discrimination and crowding-out effects, Journal of Monetary Economics, vol. 61(C), pages 114-142.

[15] Buiter, Willem H.; Anne Sibert, (2005) How the Eurosystem Treatment of Collateral in its Open Market Operations Weakens Fiscal Discipline in the Eurozone (and what to do about it), CEPR Discussion Papers 5387, C.E.P.R. Discussion Papers.

[16] Chen, Ruo; Gian Maria Milesi-Ferretti and Thierry Tressel, (2013). External imbalances in the eurozone, Economic Policy, vol. 28(73), pages 101-142, 01.

[17] Clarida, Richard H., (1990). International Lending and Borrowing in a Stochastic, Stationary Equilibrium, International Economic Review, vol. 31(3), pages 543-58, August.

[18] Coeurdacier, Nicolas and Philippe Martin, (2009). The geography of asset trade and the euro: Insiders and outsiders, Journal of the Japanese and International Economies, vol. 23(2), pages 90-113, June.

[19] Conesa, Juan Carlos; Timothy J. Kehoe, (2015) Gambling for redemption and selffulfilling debt crises. NBER Working Papers 21026, National Bureau of Economic Research.

[20] Corsetti, Giancarlo; Luca Dedola; Sylvain Leduc, (2008). International risk sharing and the transmission of productivity shocks. The Review of Economic Studies, 75.2, 443-473.

[21] Corsetti, Giancarlo; Keith Kuester; André Meier; Gernot Müller, (2014). Sovereign risk and belief-driven fluctuations in the euro area, Journal of Monetary Economics, vol. 61, January 2014, Pages 53-73.

[22] Fornaro, Luca (2014). International Debt Deleveraging, CREI Working Paper.

[23] Gopinath, Gita, Sebnem Kalemli-Ozcan, Loukas Karabarbounis, Carolina VillegasSanchez (2015). Capital Allocation and Productivity in South Europe, NBER Working Papers 21453, National Bureau of Economic Research.

[24] Guerrieri, Luca; Matteo Iacoviello and Raoul Minetti (2013). Banks, Sovereign Debt, and the International Transmission of Business Cycles, NBER International Seminar on Macroeconomics, University of Chicago Press, vol. 9(1), pages 181 - 213.

[25] Guerrieri, Veronica; Guido Lorenzoni (2011). Credit Crises, Precautionary Savings, and the Liquidity Trap, NBER Working Papers 17583, National Bureau of Economic Research.

[26] Hale, Galina; Maurice Obstfeld (2014), The Euro and The Geography of International Debt Flows, NBER Working Papers 20033, National Bureau of Economic Research. 
[27] IMF (2012), Managing Director's Global Policy Agenda International Monetary and Financial Committee, October 2012.

[28] Jaccard, Ivan; Frank Smets (2015). Structural asymmetries and financial imbalances in the eurozone, mimeo.

[29] Kalemli-Ozcan, Sebnem; Elias Papioannou and Jose Luis Peydro (2010), What Lies Beneath the Euro's Effect on Financial Integration? Currency Risk, Legal Harmonization or Trade?, Journal of International Economics 81: 75-88.

[30] Keynes, John Maynard, The German Transfer Problem, The Reparation Problem: A Discussion. II. A Rejoinder, Views on The Transfer Problem. III. A Reply, Economic Journal 39 (March 1929), 1-7, (June 1929), 172-178, (September 1929), 404-408.

[31] King, Mervyn; David Low, (2014). Measuring the "world" real interest rate. NBER Working Papers 19887, National Bureau of Economic Research.

[32] Kopecky, Karen A.; Richard MH Suen, (2010). Finite state Markov-chain approximations to highly persistent processes. Review of Economic Dynamics, 13.3: 701-714.

[33] Lane, Philip R.; Gian Maria Milesi-Ferretti (2007), The external wealth of nations mark II: Revised and extended estimates of foreign assets and liabilities, 19702004, Journal of International Economics, 73, November, 223-250.

[34] Lane, Philip R. (2012), The European Sovereign Debt Crisis, Journal of Economic Perspectives, American Economic Association, vol. 26(3), pages 49-68, Summer.

[35] Lane, Philip R. 2013. Capital Flows in the Euro Area, European Economy - Economic Papers 497, Directorate General Economic and Financial Affairs (DG ECFIN), European Commission.

[36] Lipsey, Richard G.; Kelvin Lancaster (1956). The general theory of second best. The Review of Economic sStudies, Vol. 24, No. 1, pp. 11-32

[37] Martin, Philippe; Thomas Philippon, (2015). Inspecting the Mechanism Leverage and the Great Recession in the Eurozone, mimeo.

[38] Mendoza, Enrique G. (2010). Sudden Stops, Financial Crises, and Leverage, American Economic Review, American Economic Association, vol. 100(5), pages 1941-66, December.

[39] Mendoza, Enrique G.; Vivian Z. Yue, (2012) A General Equilibrium Model of Sovereign Default and Business Cycles, The Quarterly Journal of Economics, vol. 127(2), pages 889-946.

[40] Nouy, Danièle (2012), Is sovereign risk properly addressed by financial regulation?, Financial Stability Review, Banque de France, 16, 95-106, April. 
[41] OECD (2011a). OECD Economic Outlook, Vol. 2011/2, OECD Publishing, Paris.

[42] OECD (2011b), STAN indicators Rev. 3, 2011, STAN: OECD Structural Analysis Statistics (database). DOI: http://dx.doi.org/10.1787/data-00561-en

[43] OECD/WTO (2015). Trade in value added, OECD-WTO: Statistics on Trade in Value Added (database). DOI: http://dx.doi.org/10.1787/data-00648-en

[44] Reis, Ricardo (2013). The Portugese Slump and Crash and the Euro Crisis, Brookings Papers on Economic Activity, Economic Studies Program, The Brookings Institution, vol. 46-1 (Spring), pages 143-210.

[45] Rouwenhorst, K.G., (1995). Asset Pricing Implications of Equilibrium Business Cycle Models. In: Cooley, T.F. (Ed.), Frontiers of Business Cycle Research, 294-330.

[46] Sachs, Jeffrey (1982). The Current Account in the Macroeconomic Adjustment Process, Scandinavian Journal of Economics, vol. 84, issue 2, pages 147-59.

[47] Schmitt-Grohé, Stephanie; Martn Uribe (2003). Closing small open economy models. Journal of international Economics vol. 61.1, 163-185.

[48] Siena, Daniele (2015). The European Monetary Union and Imbalances: Is it an Anticipation Story? mimeo.

[49] Thwaites, Gregory, (2014). Why are real interest rates so low? Secular stagnation and the relative price of investment goods. Centre for Macroeconomics Discussion Paper, 2014-28.

[50] Waysand, Claire; Kevin Ross and John de Guzman, (2010). European Financial Linkages: A New Look at Imbalances, IMF Working Paper, WP/10/295. 